\title{
Combined retrievals of boreal forest fire aerosol properties with a polarimeter and lidar
}

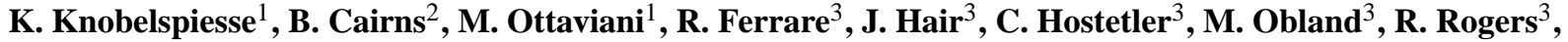 \\ J. Redemann ${ }^{4,5}$, Y. Shinozuka ${ }^{5}$, A. Clarke ${ }^{6}$, S. Freitag ${ }^{6}$, S. Howell ${ }^{6}$, V. Kapustin ${ }^{6}$, and C. McNaughton ${ }^{6}$ \\ ${ }^{1}$ NASA Postdoctoral Program Fellow, NASA Goddard Institute for Space Studies, New York, USA \\ ${ }^{2}$ NASA Goddard Institute for Space Studies, New York, USA \\ ${ }^{3}$ NASA Langley Research Center, Hampton, Virginia, USA \\ ${ }^{4}$ Bay Area Environmental Research Institute, Sonoma, CA, USA \\ ${ }^{5}$ NASA Ames Research Center, Moffett Field, California, USA \\ ${ }^{6}$ University of Hawaii, Honolulu, Hawaii, USA
}

Received: 27 January 2011 - Published in Atmos. Chem. Phys. Discuss.: 9 March 2011

Revised: 7 July 2011 - Accepted: 12 July 2011 - Published: 20 July 2011

\begin{abstract}
Absorbing aerosols play an important, but uncertain, role in the global climate. Much of this uncertainty is due to a lack of adequate aerosol measurements. While great strides have been made in observational capability in the previous years and decades, it has become increasingly apparent that this development must continue. Scanning polarimeters have been designed to help resolve this issue by making accurate, multi-spectral, multi-angle polarized observations. This work involves the use of the Research Scanning Polarimeter (RSP). The RSP was designed as the airborne prototype for the Aerosol Polarimetery Sensor (APS), which was due to be launched as part of the (ultimately failed) NASA Glory mission. Field observations with the RSP, however, have established that simultaneous retrievals of aerosol absorption and vertical distribution over bright land surfaces are quite uncertain. We test a merger of RSP and High Spectral Resolution Lidar (HSRL) data with observations of boreal forest fire smoke, collected during the Arctic Research of the Composition of the Troposphere from Aircraft and Satellites (ARCTAS). During ARCTAS, the RSP and HSRL instruments were mounted on the same aircraft, and validation data were provided by instruments on an aircraft flying a coordinated flight pattern. We found that the lidar data did indeed improve aerosol retrievals using an optimal estimation method, although not primarily because of the contraints imposed on the aerosol vertical distribution. The more useful piece of information from the HSRL was the total
\end{abstract}

Correspondence to: K. Knobelspiesse (kirk.d.knobelspiesse@nasa.gov) column aerosol optical depth, which was used to select the initial value (optimization starting point) of the aerosol number concentration. When ground based sun photometer network climatologies of number concentration were used as an initial value, we found that roughly half of the retrievals had unrealistic sizes and imaginary indices, even though the retrieved spectral optical depths agreed within uncertainties to independent observations. The convergence to an unrealistic local minimum by the optimal estimator is related to the relatively low sensitivity to particles smaller than $0.1(\mu \mathrm{m})$ at large optical thicknesses. Thus, optimization algorithms used for operational aerosol retrievals of the fine mode size distribution, when the total optical depth is large, will require initial values generated from table look-ups that exclude unrealistic size/complex index mixtures. External constraints from lidar on initial values used in the optimal estimation methods will also be valuable in reducing the likelihood of obtaining spurious retrievals.

\section{Introduction}

Polarimetric remote sensing is a valuable tool for the study of atmospheric particles. In the 1970's, Hansen and Hovenier (1974) used observations of (linear) polarization in sunlight reflected from Venus to conclude that the planet is shrouded by sulfuric acid clouds (Hansen and Hovenier, 1974). Today, the field has grown to include remote sensing of atmospheric aerosol particles surrounding our own planet. Aerosols are airborne particulate matter that are of interest because of the variety of ways they can affect the global

Published by Copernicus Publications on behalf of the European Geosciences Union. 
climate, and because this interaction is not well understood. Unlike the greenhouse gases associated with climate change, aerosols typically survive in the atmosphere for only days or weeks, and are thus highly regional. They have both natural and anthropogenic sources and highly variable optical properties. For these reasons, the Intergovernmental Panel on Climate Change has identified aerosols as a major source of uncertainty in the radiative forcing of climate (IPCC, 2007). Much of this uncertainty is due to inadequacies in providing appropriate and comprehensive information for climate models (Mishchenko et al., 2004, 2007b).

The Aerosol Polarimetry Sensor (APS), which was part of the NASA Glory orbital mission, was intended to expand the quantity and quality of atmospheric aerosol descriptive parameters. Unfortunately, the Glory spacecraft failed to reach orbit during its launch on 4 March 2011. APS was to use polarimetric observations of reflected sunlight at about 240 viewing angles in each of nine channels at visible and near infra-red wavelengths (Mishchenko et al., 2007a). Aerosol property retrievals were to be determined by optimizing a radiative transfer simulation to match observed linear and polarized reflectance. In order to prepare for the launch of APS, the Research Scanning Polarimeter (RSP) was constructed (Cairns, 2003). The RSP is similar to the APS, but is deployed on an airborne, rather than orbital, observation platform. The RSP has been used in a number of field campaigns in the last decade to test the ability to accurately measure a variety of aerosol types (Cairns et al., 1997; Chowdhary et al., 2001, 2002, 2005a,b; Cairns, 2003; Elias et al., 2004; Waquet et al., 2009). Despite the loss of Glory, RSP will continue to be deployed in the field.

In June and July of 2008, the RSP participated in the summer phase of the Arctic Research of the Composition of the Troposphere from Aircraft and Satellites (ARCTAS) field campaign (Jacob et al., 2010). ARCTAS was the NASA contribution to the international Polar Study using Aircraft, Remote Sensing, Surface Measurements and Models, of Climate, Chemistry, Aerosols, and Transport (POLARCAT) program of observations for the International Polar Year. While stationed in Northern Canada, the RSP (and other instruments associated with ARCTAS) observed smoke aerosols from boreal forest fires. Biomass Burning (BB) aerosols tend to be both highly absorbing and unevenly distributed vertically in the atmosphere. The effects of aerosol absorption and vertical distribution were found to have similar impacts on the polarized reflectances observed over bright desert surfaces which increases the uncertainty in the retrieval of both aspects of the aerosol distribution (Waquet et al., 2009). Furthermore, retrievals of ocean optical properties may be affected by incorrect aerosol retrievals due to aerosol vertical distribution errors (Duforêt et al., 2007). Orbital scanning polarimeter observations could therefore benefit from a data merger with active instruments such as the Cloud-Aerosol Lidar with Orthogonal Polarization (CALIOP) onboard the Cloud-Aerosol Lidar and
Infrared Pathfinder Satellite Observation (CALIPSO) satellite (Winker et al., 2003, 2004, 2007). CALIOP can determine the vertical layering of aerosols and reduce the ambiguity in BB aerosol retrievals due to aerosol vertical distribution uncertainty. During ARCTAS, the RSP flew onboard the NASA B-200 aircraft, which also carried the High Spectral Resolution Lidar (HSRL) (Hair et al., 2001, 2008, and Rogers et al., 2009). In addition, the B-200 flew coordinated missions with an aircraft containing instrumentation whose data can validate RSP results. ARCTAS was therefore the ideal mission to evaluate combined polarimeter and lidar aerosol property retrievals for near source smoke, and that is the main goal of this paper.

In the next section, we will provide an overview of the RSP retrieval approach. We will also briefly describe the HSRL and in situ data collection and processing, and provide references to more detailed discussions. Next, we will present the results of our tests. RSP retrievals were performed with and without HSRL data, and were compared to in situ data to test their success. Finally, implications of these tests for future RSP/HSRL measurements will be discussed.

\section{Method}

\subsection{RSP instrument specifics}

The Research Scanning Polarimeter is an airborne prototype for the Aerosol Polarimetery Sensor. The main goals of both RSP and APS are to retrieve a complete suite of aerosol and cloud microphysical parameters from orbit (Mishchenko et al., 2004, 2007b). Both instruments have similar characteristics, but since the data we analyze in this paper were from RSP, that instrument alone will be discussed here. The RSP has nine optical channels with center wavelengths of 410 , $470,555,670,865,960,1590,1880$ and $2250 \mathrm{~nm}$, and is a passive, along track, scanning (not imaging), device. Each RSP scan begins about $60^{\circ}$ forward of nadir in the direction of aircraft motion, and samples at $0.8^{\circ}$ intervals to about $60^{\circ}$ aft of nadir. The instantaneous field of view (IFOV) of the RSP is fourteen milliradians. For an average (during ARCTAS) aircraft height of $8680 \mathrm{~m}$ above sea level and ground elevation of $370 \mathrm{~m}$, this corresponds to ground pixel size of about $120 \mathrm{~m}$. For observation of elevated smoke plumes such as ours, the spatial resolution is about $65 \mathrm{~m}$.

The RSP/APS observes linearly polarized and total reflectance. This can be described by the first three terms of the Stokes polarization vector (Hansen and Travis, 1974), I, $Q$ and $U . I$ is the total radiance, while $Q$ and $U$ indicate the direction and magnitude of the linearly polarized radiance. The fourth term in the polarization vector, $V$, represents circular polarization, which is very small for atmospheric aerosols (Kawata, 1978, for spherical particles), and is neglected in the analysis of RSP data. From a remote sensing standpoint, it is useful to express the polarization 
components of the Stokes vector in terms of reflectance. This takes the exo-atmospheric radiance into account, and is calculated as follows,

$$
\begin{aligned}
& R_{I}=\frac{I \pi r_{\mathrm{o}}^{2}}{F_{\mathrm{o}} \cos \theta_{\mathrm{s}}} \\
& R_{Q}=\frac{Q \pi r_{\mathrm{o}}^{2}}{F_{\mathrm{o}} \cos \theta_{\mathrm{s}}} \\
& R_{U}=\frac{U \pi r_{0}^{2}}{F_{\mathrm{o}} \cos \theta_{\mathrm{s}}}
\end{aligned}
$$

where $F_{\mathrm{o}}$ is the annual average solar exo-atmospheric irradiance $\left(\mathrm{W} \mathrm{m}^{-2}\right)$, spectrally weighted for the particular RSP band, $r_{\mathrm{O}}$ is the solar distance in $\mathrm{AU}$ (thus compensating for solar distance deviation from average throughout the year), and $\theta_{\mathrm{s}}$ is the solar zenith angle. The RSP instrument has a high accuracy $(0.2 \%)$ of $R_{Q}$ and $R_{U}$ relative to $R_{I}$, as the same detectors are used to measure intensity and linear polarization, and because calibration of their relative gain is performed with each scan.

For each scene, the RSP makes observations of $R_{I}, R_{Q}$ and $R_{U}$ in nine wavelengths for 150 view angles. This provides upwards of four thousand measurements that are used to determine the aerosol optical properties that provide an optimal fit to the observations. In practice, far fewer measurements are used (for reasons described below), and there is also a strong correlation between observations at different view angles. However, this is sufficient information to retrieve the half dozen or so optically important parameters for each aerosol size mode. Furthermore, the broad spectral range of the RSP observations allows the surface to be constrained almost independently of the atmospheric state.

\subsection{ARCTAS and data selection}

The ARCTAS field campaign involved three aircraft in two, three week segments in 2008. The RSP was deployed during the summer (June-July) phase of the campaign (ARCTAS-B) on a Beechcraft King Air B-200 aircraft based at the NASA Langley Research Center in Hampton, Virginia. One of the primary goals of ARCTAS-B was to observe and characterize boreal forest fire smoke (Jacob et al., 2010), so the B200 was based in Yellowknife, Northwest Territories, Canada $\left(62^{\circ} \mathrm{N}, 114^{\circ} \mathrm{W}\right)$ for this purpose. The B-200 flew coordinated flights with another ARCTAS aircraft during satellite overpass times. This aircraft, a Lockheed P-3 Orion from the NASA Wallops Flight Facility in Wallops, Virginia, carried a variety of instrumentation, including the Hawaii Group for Environmental Aerosol Research (HiGEAR) aerosol in situ sampling instruments. Furthermore, the Ames Airborne Tracking Sunphotometer (AATS-14), a fourteen channel sun tracking sun photometer, was installed on the P-3. RSP data collected during these times is ideal for the validation of RSP aerosol retrievals of vertically inhomogeneous, highly absorbing aerosols. We chose to study a small data subset from the smoke plume of a recent boreal forest fire. Surveys of other boreal forest fire aerosols can be found elsewhere (e.g. Eck et al., 2003, 2009; Koppmann et al., 2005; Reid et al., 2005a,b).

A scene on 30 June 2008, was selected for analysis. On that day, the B-200 overflew a smoke plume downwind from its source in conditions that were otherwise nearly free of aerosols. The fire was in northern Sasketchewan, Canada $\left(58.41^{\circ} \mathrm{N}, 106.81^{\circ} \mathrm{W}\right)$ and had been burning since 29 June. Natural Resources Canada, in its forest inventory of 2001 (CanFI2001), characterizes this region as a mixed soft and hardwood boreal forest. RSP observations were made about $130 \mathrm{~km}$ downwind from the source (see Fig. 1). Back trajectory analysis (Fuelberg et al., 2010) indicates that the smoke was $2 \mathrm{~h}$ and 17 min old at this point, although it should be noted that this analysis did not account for local dynamics associated with the fire. We consider this scene to be ideal for a number of reasons, as described below.

1. The HSRL was operational at the time of RSP observation, indicating an optically thick plume detached from the surface.

2. The B-200 aircraft (containing the RSP and HSRL) was in a coordinated flight path with the P-3 aircraft (containing AATS and HiGEAR), which was under-flying the B-200 at a mean altitude of $627 \mathrm{~m}$ a.s.l. (above sea level).

3. A MODIS-Aqua image was collected about forty minutes prior to the scene. The "truecolor" version of this scene provides the spatial context as observed in Fig. 1.

4. Aircraft orientation was close to the solar principal plane (the plane containing both the solar illumination and observation vectors), providing a large range of scattering angles for use during optimization of RSP data.

5. The atmospheric state outside the plume was exceptionally free of aerosols. An RSP aerosol retrieval performed prior to contact with the plume yielded an aerosol optical thickness of 0.07 at $555 \mathrm{~nm}$, while AATS observations from the same location found an optical thickness of 0.04 at $520 \mathrm{~nm}$.

6. Aircraft geometry, as provided by an onboard inertial monitoring unit, had relatively low uncertainties.

7. Back trajectory analysis (Fuelberg et al., 2010), combined with the Canadian Wildland Fire Information System database (Canada, 2009) shows that the airmass in the days prior to the observation did not come into contact with any significant sources of biomass burning (or other) aerosols. 


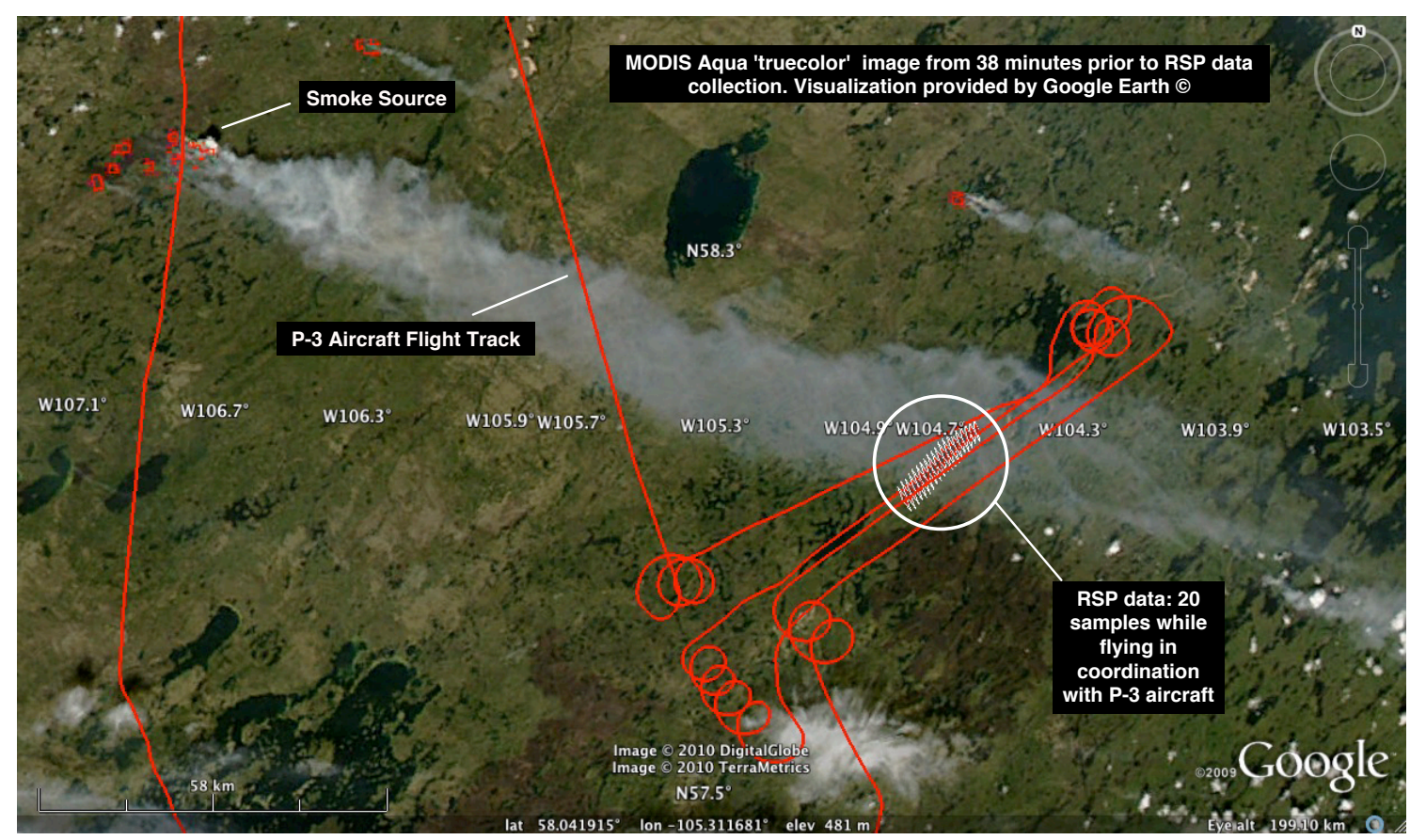

Fig. 1. MODIS Aqua satellite fire imagery from 19:50 UTC. The RSP observations, indicated by the ordered white polygons at the right, were collected at 20:28 UTC on the B-200 aircraft. The flight track of the P-3 aircraft is shown in red. The portion of the P-3 flight under the indicated RSP observations was coordinated to occur at the same time. Google Earth was used to visualize these data.

Aerosol retrieval optimization was performed individually for about twenty segments in each scene. To reduce noise, each segment is an average of five RSP scans. We used this approach (rather than performing a single optimization on an average of a larger number of scans) to test the consistency of the optimization approach, and to allow for the compensation, or quantification, of the effects of scene heterogeneity and changing aircraft geometry. In situ and sun photometer data on the P-3 indicate that aerosol optical thickness varies across the smoke plume, while intensive properties such as single scattering albedo remain mostly constant (see figures in Sect. 3). We would therefore expect retrieved aerosol number concentration, $n$, (and thus optical thickness, $\tau$ ), to vary across the plume, whereas intensive properties (size and composition) should vary less. For the time, location, solar geometry and other details associated with each segment, see Table A1.

\subsection{Optimization approach}

We retrieved aerosol optical properties by matching the output from a radiative transfer model to polarized and unpolarized reflectances observed by the RSP. The LevenbergMarquardt approach, which is a standard method for the solution of non-linear least squares minimization problems, was used to find that match. With the exception of some methodological and software differences (outlined below), we used the approach described in detail in Waquet et al. (2009). Generally speaking, the radiative transfer model and software is identical, using Lorenz-Mie computations of single scattering properties and the Doubling and Adding approach to create multiple scattering in a layered atmosphere (Mishchenko and Travis, 2008; Hansen and Travis, 1974). Optimization is performed differently than in Waquet et al. (2009), with a slightly different cost function and measurement vector and using publicly available software to perform the Levenberg-Marquardt optimization. This software, implemented in the Interactive Data Language (IDL) as MPFIT (Markwardt, 2009), is a translation of the original FORTRAN language MINPACK-1 (Moré, 1977) solver, and is well documented. For this reason, we chose to use MPFIT, as it is faster and more flexible than the optimization software created for Waquet et al. (2009) (although both techniques are appropriate). Furthermore, numerical and computational issues associated with techniques such as this have been addressed in the creation of MINPACK-1 and MPFIT. However, there are often subtle differences between different implementations of the Levenberg-Marquardt approach, we describe our methodology in more detail below.

\subsubsection{Optimal estimation}

Optimal estimation is performed by the minimization of a, generally nonlinear, cost function. The cost function incorporates information about the uncertainty in the measurements so that the estimate that minimizes the cost function is optimal in the sense that it provides the best possible fit to the measurements given their uncertainties. In our case, 
this cost function, $\Phi$, is the sum of squares of differences between the observational data and model calculation vectors weighted by their total uncertainty,

$\Phi(\boldsymbol{x})=\frac{1}{2}\|\boldsymbol{F}(\boldsymbol{x})\|^{2}=\frac{1}{2}\left\|\frac{\boldsymbol{Y}-\boldsymbol{G}(\boldsymbol{x})}{\mathbf{C}_{T}}\right\|^{2}$

where $\boldsymbol{Y}$ is the measurement vector and $\boldsymbol{G}(\boldsymbol{x})$ is the modeled vector for aerosol parameters $\boldsymbol{x}$. We use $\|$.$\| to indicate the$ use of the Euclidean norm. Note that, unlike Waquet et al. (2009), this cost function depends only on the differences between observational data and model results, and does not use and additional side constraint on the distance from the initial model parameters. In this sense, it is free to explore the parameter space available during optimization with a minimized dependence on initial conditions. $\mathbf{C}_{T}$ is the measurement error covariance matrix, which can be broken down into component errors as

$\mathbf{C}_{T}=\mathbf{C}_{\varepsilon}+\mathbf{C}_{\mathrm{cal}}+\mathbf{C}_{\mathrm{pol}}+\mathbf{C}_{\mathrm{ag}}+\mathbf{C}_{y}+\mathbf{C}_{\mathrm{p}}$.

Following the example of Waquet et al. (2009), the instrumental noise, $\mathbf{C}_{\varepsilon}$ is shot noise limited, $\mathbf{C}_{\mathrm{cal}}$ is the absolute radiometric calibration uncertainty of $3 \%$, and $\mathbf{C}_{\mathrm{pol}}$ accounts for the uncertainty in the relative polarimetric accuracy, which increases with the degree of linear polarization.

$$
\begin{aligned}
& \mathbf{C}_{\varepsilon, i}=10^{-7} \cos \theta_{\mathrm{s}} R_{I}(i) \\
& \mathbf{C}_{\mathrm{cal}, i}=\left(0.03 R_{Q}(i)\right)^{2} \\
& C_{\mathrm{pol}, i}=\left(0.001\left[R_{I}(i)+\left|R_{Q}(i)\right|\right]\right)^{2}
\end{aligned}
$$

where the index, $i$, indicates that all the uncertainties are spectral band and view angle dependent and it is assumed that the measurement error covariance matrix is diagonal.

Waquet et al. (2009) uses a fourth term in Eq. (3) which accounts for errors modeling the surface reflectance. They label this term as $\mathbf{C}_{\mathrm{F}}$. The contribution of $\mathbf{C}_{\mathrm{F}}$ to the total error is very small, and since the smoke plume we observe is quite optically thick, for this case we can (and do) neglect $\mathbf{C}_{\mathrm{F}}$. For the data we analyze here, we found two additional sources of uncertainty that must be included in the error budget for the observations. The variability encountered when averaging several scans of an inhomogeneous plume requires a new term, $\mathbf{C}_{\mathrm{ag}}$, which represents the sampling uncertainty for that observation and is the standard deviation for the averaged set of scans for each view zenith angle. We have also added two terms to account for uncertainties in the aircraft geometry. $\mathbf{C}_{y}$ is the uncertainty in the observed polarized reflectance caused by uncertainties in the aircraft heading angle (yaw), which expresses itself as an incorrect view azimuth angle. We estimated the magnitude of this uncertainty by shifting the observed data for a heading error of $0.5^{\circ}$, and taking the difference between the observed and shifted observation. The $0.5^{\circ}$ shift was empirically determined based on data variability. For $R_{Q}$, we add to $\mathbf{C}_{y}$ the error from an incorrect rotation into the scattering plane. $\mathbf{C}_{\mathrm{p}}$ is the uncertainty in the observed polarized reflectance caused by aircraft pitch angle, which expresses itself as an incorrect view zenith angle. Uncertainty is computed in a manner similar to $\mathbf{C}_{y}$, and we again used a value of $0.5^{\circ}$. Both estimates of geometry uncertainty were determined empirically based on data variance. Typically, the largest contributer to measurement uncertainty is aircraft pitch, closely followed by sampling uncertainty due to scene heterogeneity. Absolute calibration uncertainties are usually a much smaller contributer to the observation errors than the uncertainties in aircraft geometry and scene variability.

The above covariance matrix definition applies to components of the measurement vector associated with the polarized reflectance. The covariance for the total reflectance is slightly different. Polarimetric accuracy does not affect the uncertainty in the total reflectance, instrumental noise remains the same, and the radiometric calibration uncertainty is now $3 \%$ of the total reflectance.

$\mathbf{C}_{\mathrm{cal}}(i)=\left[0.03 R_{I}(i)\right]^{2}$

The assumption of uncorrelated measurement errors is commonly used (Lebsock et al., 2007; Hasekamp, 2010) and is valid for the instrument noise, and to a lesser extent for polarimetric accuracy. For radiometric accuracy and aircraft attitude, there will be correlation between measurement uncertainties at different view angles. For the data analyzed here, however, scene heterogeneity and random variations in aircraft attitude dominate the error budget and justify the assumption of uncorrelated measurements errors. Future work will incorporate error correlation for aerosol retrievals over the ocean, where a lack of surface heterogeneity does not overshadow the effect of correlations between measurement errors for different view angles.

Starting from selected initial values for the aerosol parameters, $\boldsymbol{x}_{\mathrm{o}}$ (see Sect. 2.3.3), the Levenberg-Marquardt algorithm provides an iterative search for the parameter vector, $\boldsymbol{p}$, that minimizes the cost function $\Phi\left(\boldsymbol{x}_{\mathrm{o}}+\boldsymbol{p}\right)$ and thus gives the optimal solution $\boldsymbol{x}=\left(\boldsymbol{x}_{\mathrm{O}}+\boldsymbol{p}\right)$. The iteration proceeds by constraining the minimization of the cost function at any step to lie within a trust region, $\Delta_{k}$, around the current iteration step. A linearization about the current state vector, $\boldsymbol{x}_{k}$, is used to determine the size of the next step. At any given step, we are therefore attempting to solve

$\min \left\{\left\|\mathbf{F}\left(\boldsymbol{x}_{k}\right)+\mathbf{J}_{k} \boldsymbol{p}_{k}\right\|:\left\|\mathbf{D}_{k} \boldsymbol{p}_{k}\right\| \leq \Delta_{k}\right\}$

where $k$ is an index indicating how many steps have been made, and $\mathbf{J}_{k}$ is the Jacobian matrix, which expresses the forward model sensitivity to parameter change. The notation : means "such that".

$$
\mathbf{J}_{k}=\left.\frac{\partial \mathbf{F}(\boldsymbol{x})}{\partial \boldsymbol{x}}\right|_{\boldsymbol{x}=\boldsymbol{x}_{k}}
$$

$\mathbf{D}_{k}$ is a diagonal, but not an identity, matrix. This was introduced by Marquardt to allow for a large step in a direction 
with low curvature and a small step in a direction with high curvature. Heuristically, this serves to reduce the effects of a narrow valley with a relatively flat floor and is calculated as part of the iteration with the formula

$$
\begin{aligned}
& \mathbf{D}_{k}=\operatorname{diag}\left(d_{1}^{(k)}, \ldots, d_{n}^{(k)}\right) \\
& d_{i}^{(k)}=\max \left[d_{i}^{(k-1)},\left\|\left.\frac{\partial \mathbf{F}(\boldsymbol{x})}{\partial x_{i}}\right|_{\boldsymbol{x}=\boldsymbol{x}_{k}}\right\|\right] .
\end{aligned}
$$

The Levenberg-Marquardt method is based on the theorem that if $\boldsymbol{p}^{*}$ is a solution to Eq. (6), then $\boldsymbol{p}^{*} 4=\boldsymbol{p}(\Upsilon)$ for some $\Upsilon \geq 0$ where

$$
\boldsymbol{p}(\Upsilon)=-\left(\mathbf{J}_{k}^{T} \mathbf{J}_{k}+\Upsilon \mathbf{D}_{k}^{T} \mathbf{D}_{k}\right)^{-1} \mathbf{J}_{k}^{T} \mathbf{F}\left(\boldsymbol{x}_{k}\right)
$$

The constrained minimization is then implemented by the following algorithm, from Moré (1977)

1. Given $\Delta_{k}>0$, find $\Upsilon_{k} \geq 0$ such that if

$$
\left(\mathbf{J}_{k}^{T} \mathbf{J}_{k}+\Upsilon_{k} \mathbf{D}_{k}^{T} \mathbf{D}_{k}\right) \boldsymbol{p}_{k}=-\mathbf{J}_{k}^{T} \mathbf{F}\left(\boldsymbol{x}_{k}\right)
$$

then either $\Upsilon_{k}=0$ and $\left\|\mathbf{D}_{k} \boldsymbol{p}_{k}\right\| \leq \Delta_{k}$, or $\Upsilon_{k}>0$ and $(1-\sigma) \Delta_{k}<\left\|\mathbf{D}_{k} \boldsymbol{p}_{k}\right\|<(1+\sigma) \Delta_{k}$. $\sigma$ is the relative error within which the iterative estimate of $\Upsilon_{k}$ is required to meet $\left\|\mathbf{D}_{k} \boldsymbol{p}_{k}\right\|=\Delta_{k}$.

2. If $\left\|\mathbf{F}\left(\boldsymbol{x}_{k}+\boldsymbol{p}_{k}\right)\right\|<\left\|\mathbf{F}\left(\boldsymbol{x}_{k}\right)\right\|$ then set $\boldsymbol{x}_{k+1}=\boldsymbol{x}_{k}+\boldsymbol{p}_{k}$. Otherwise, shrink the trust region $\left(\Delta_{k+1}=\frac{1}{2} \Delta_{k}\right)$ and return to step 1, without modifying $\boldsymbol{x}$ and $\mathbf{J}$.

3. Choose $\Delta_{k+1}$. The ratio of the actual reduction of the cost function to the predicted reduction is the criterion for adjusting $\Delta$, viz.,

$$
\rho_{k}=\frac{\left\|\mathbf{F}\left(\boldsymbol{x}_{k}\right)\right\|^{2}-\left\|\mathbf{F}\left(\boldsymbol{x}_{k}+\boldsymbol{p}_{k}\right)\right\|^{2}}{\left\|\mathbf{F}\left(\boldsymbol{x}_{k}\right)\right\|^{2}-\left\|\mathbf{F}\left(\boldsymbol{x}_{k}\right)+\mathbf{J}_{k} \boldsymbol{p}_{k}\right\|^{2}} .
$$

The value of $\rho_{k}$ is used to determine $\Delta_{k+1}$ as follows

- if $\rho_{k} \leq 1 / 4$, then set $\Delta_{k+1}<\Delta_{k}$ using the method in Fletcher (1971).

$$
\begin{aligned}
& \text { - if } \frac{1}{4} \leq \rho_{k} \leq \frac{3}{4} \text { and } \Upsilon_{k}=0 \text {, set } \Delta_{k+1}=2\left\|\mathbf{D}_{k} \boldsymbol{p}_{k}\right\| \\
& \text { - if } \frac{1}{4} \leq \rho_{k} \leq \frac{3}{4} \text { and } \Upsilon_{k}>0 \text {, set } \Delta_{k+1}=\Delta_{k} \\
& \text { - if } \rho_{k} \geq 3 / 4 \text {, then set } \Delta_{k+1}=2\left\|\mathbf{D}_{k} \boldsymbol{p}_{k}\right\| .
\end{aligned}
$$

To summarize, if the predicted and actual reductions in cost functions are similar then the trust region is increased, whereas if they are widely disparate the trust region is decreased based on a prescription by Fletcher (1971).

4. Update $\mathbf{D}_{k+1}$ using Eq. (8).
This iteration continues until either the step size is less than the expected uncertainty in state (aerosol parameter) space, or the reduction in the cost function is small. Once the iteration is complete, the retrieval error covariance matrix, $\mathbf{C}_{x}$, can be obtained from the Jacobians computed in the final step using the equation

$\mathbf{C}_{x}=\left(\mathbf{J}^{T} \mathbf{C}_{T} \mathbf{J}\right)^{-1}$.

Uncertainty associated with retrieved parameters is the square root of the diagonal elements of $\mathbf{C}_{x}$. The error covariance matrix can also be used to compute retrieval uncertainty of a parameter that is not directly retrieved during optimization (such as the aerosol optical thickness, see Table 2), provided the dependent variables of the required parameter are part of the retrieval vector $\boldsymbol{x}$. This is done by computing the sensitivity of the indirectly retrieved parameter in the forward model to changes in each of the retrieved parameters. Following the method of Hasekamp and Landgraf (2007), the uncertainty in the indirectly retrieved parameter (denoted with the subscript $A$ ) is

$\sigma_{A}^{2}=\sum_{i=1}^{N} \sum_{j=1}^{N} \mathbf{C}_{x, i, j} \frac{\left.\partial G_{a} \boldsymbol{x}\right)}{\partial x_{j}}$

where $i$ and $j$ are subscripts identifying elements of the retrieved parameter vector (which has a length of $N$ ). $G_{a}(\boldsymbol{x})$ is the forward model value for the indirectly retrieved parameter, $A$, evaluated at the optimal estimate, $\boldsymbol{x}$ (note that this is a scalar value not in the same space as $\mathbf{G}(\boldsymbol{x})$ ). We compute the forward model sensitivity for an indirectly retrieved parameter $\left(\frac{\partial G_{a}(x)}{\partial x}\right)$ numerically, with a post-processing step after optimization is finished.

We chose this form of the Levenberg-Marquardt method for several reasons, which we briefly describe here. For more details about this method and its convergence properties, see More (1977), or the documentation of the MINPACK FORTRAN subroutines on which our technique is based (www.netlib.org/minpack/ and Moré et al., 1980). The Levenberg-Marquardt technique is robust, and is efficient in its use of forward model calculations. Our vertically inhomogeneous vector radiative transfer model is computationally intensive, so it is not feasible to make multiple forward calculations to determine an optimal parameter $\Upsilon_{k}$. The algorithm given above uses an iterative estimate of $\Upsilon_{k}$, but the iteration is one that finds a step within a trust region that does not require additional forward model or Jacobian calculations (Hebden, 1973). For a trust region criterion of $10 \%$ ( $\Delta=0.1$ ), $\Upsilon$ is typically found within two iterations (Moré, 1977). The trust region grows whenever the predicted and actual cost function reductions are similar, so the transition between the steepest descent and Newton-Gauss components of the Levenberg-Marquardt technique is heuristically reasonable, as whenever the next step is within the trust region an efficient Newton-Gauss step is used. 


\subsubsection{The measurement vector}

The measurement vector, $\boldsymbol{Y}$, contains observations of the $Q$ component of polarized reflectance $\left(R_{Q}\right)$ at six wavelength bands, and total reflectance $\left(R_{I}\right)$ for one band. In each band, observations were taken from a scan between $20^{\circ}$ forward in the aircraft and $40^{\circ}$ aft. Since the RSP has an angular resolution of 14 milliradians, this corresponds to 75 individual measurements in each scan, for a total of 450 observations of $R_{Q}$ and 75 observation of $R_{I}$. The polarization frame of reference was rotated into the scattering plane (the plane containing both the solar and observation vectors) so that $R_{Q}$ measurements alone are sufficient to represent the linear polarization $\left(R_{U}\right.$ is negligible for single scattering in the scattering plane). For the purposes of optimization using data near solar backscatter, the choice of $R_{Q}$ is preferable to the polarized reflectance $\left(R_{\mathrm{p}}=\sqrt{R_{Q}^{2}+R_{U}^{2}}\right)$ that was used in Waquet et al. (2009). $R_{Q}$ is a signed measure and makes more effective use of observed neutral points than $R_{\mathrm{p}}$.

The six wavelength bands used for $R_{Q}$ were centered at $410,470,555,670,865$ and $1590 \mathrm{~nm}$. Three RSP bands were not used. Bands centered at 960 and $1880 \mathrm{~nm}$ are designed to allow the estimation of column water vapor and the identification and characterization of cirrus clouds, respectively. The $2250 \mathrm{~nm}$ band is used to characterize the total and polarized surface reflectance for the radiative transfer model (see Sect. 2.3.3). Our particular scene contains optically thick smoke aerosols, so we also used one short wavelength $R_{I}$ band $(410 \mathrm{~nm})$ in the optimization. Observations at this band have almost no contribution from surface reflectance, since surface reflectance is minimal in the blue unless it is covered by snow or ice (Hsu et al., 2006; Guanter et al., 2008) and the large aerosol load obscures what is reflected. Nevertheless, we used the methodology of Kaufman et al. (1997) to characterize $R_{I}$ at $410 \mathrm{~nm}$ based on observations at $2250 \mathrm{~nm}$, but should be insensitive to the uncertainty in this approach.

The measurement vectors were averages of five consecutive scans (a "segment" as described above). Each scan is composed of data that have been reorganized so that all views point to a specific location, at a specific altitude, in the atmosphere. This is essential to reduce heterogeneity in the aerosol properties and loading within each segment. We performed this data reorganization so that each segment contains all of the observations, at different zenith angles, of a point at an altitude of $3800 \mathrm{~m}$.

\subsubsection{The radiative transfer model}

The radiative transfer model, $\mathbf{G}(\boldsymbol{x})$, is actually two nested models. The inner model computes single scattering properties of bi-modal log-normal size distributions of aerosols using a Mie code for spheres (Hansen and Travis, 1974). The elements of the retrieval vector required by the single scattering model are the complex refractive index, $m$, effective radius, $r_{\mathrm{e}}$, and effective variance, $v_{\mathrm{e}}$, for each size mode. The smaller size mode, which we denote hereafter with a f subscript, represents "fine" aerosols that are typically the product of chemical processes, while the larger, "coarse" mode, denoted hereafter with a c subscript, represents larger aerosols that are the result of a mechanical process. We expect the fine mode to dominate in our scene, since smoke aerosols are chemically generated. We also expect that Mie models of spheres are adequate expressions of our aerosols. Indeed, the HSRL depolarization observations are very low, indicating spherical particle dominance (see Sect. 2.4.1). Furthermore, it is believed that smoke aerosols that have aged for an hour or more generally collapse into compact shapes that are well described, optically, by spheres (Martins et al., 1998; Reid and Hobbs, 1998; Abel et al., 2003; Liu et al., 2008). The doubling and adding (DA) technique is then used to compute the upwelling, downwelling and reflected polarized radiance fields generated by multiple scattering in an inhomogeneous atmosphere (Hansen and Travis, 1974; De Haan et al., 1987). The additional retrieval vector elements required for DA calculation are the vertical distribution of aerosol number concentration for each mode $\left(n_{\mathrm{f}}\right)$ and $\left(n_{\mathrm{c}}\right)$. The result is assembled into a vector representing the geometry and wavelengths required to fill $\mathbf{G}(\boldsymbol{x})$, and used in the optimization.

The radiative transfer model also requires that the ground reflectance is specified. For polarized reflectance, we can utilize established assumptions about surface polarized reflectance. Polarized reflectance of natural surfaces (such as the epicuticular wax coating the surfaces of leaves or the mineral facets of exposed rock) will be dominated by interactions at the surface, as bulk scattering within the material tends to be weakly polarized. Fresnel reflectance off surface facets is thus an appropriate basis for modeling the polarized surface reflectance (Vanderbilt et al., 1985; Grant, 1987; Vanderbilt and Grant, 1991; Breon et al., 1995; Nadal and Breon, 1999; Cairns, 2003; Elias et al., 2004; Waquet et al., 2009). Since Fresnel polarized reflectance depends mainly on geometry and the real component of the refractive index, it exhibits little spectral variance. This is because most surface materials have a minimal real refractive index spectral variance (the imaginary component of the refractive index does vary spectrally and gives total surface reflectances color). We can therefore use the longest wavelength channel $(2250 \mathrm{~nm})$, where aerosol effects are smallest, to characterize the surface reflectance at all wavelengths. This is used as the lower boundary condition in the DA radiative transfer model. In practice, the Fresnel polarized reflectance model is scaled to an appropriate value to match observed reflectances for each scene in order to account for surface roughness or variability in the real refractive index. We use a single scaling coefficient for all geometries, which differs from Waquet et al. (2009), who used a value that varied with geometry. This simplification is feasible for our analysis because of the relatively weak contribution of the polarized surface reflectance 
due to optically thick aerosols, and allows the use a data closer to the solar backscattering angle.

For unpolarized ground reflectance, observations at $2250 \mathrm{~nm}$ were fit to the "RossThick-LiSparse" kernel based, bidirectional reflectance distribution function (BRDF) model. Fitting to the BRDF model mimicked the NASA Moderate-Resolution Imaging Spectroradiometer (MODIS) surface reflectance retrieval methodology (Lucht et al., 2000) and was performed previously with the RSP instrument in central Oklahoma in the United States (Knobelspiesse et al., 2008). The results were multiplied by 0.25 and used as the reflectance at $410 \mathrm{~nm}$. This is similar to the approximation of Kaufman et al. (1997) for MODIS retrievals of aerosol properties over land. While it has been found that the 0.25 scaling is not appropriate for all surfaces and viewing angles (Gatebe et al., 2001 and Remer et al., 2001), the variation is small enough to be rendered irrelevant by the optically thick aerosol layer obscuring the surface. For example, the retrieved aerosol optical thickness at $410 \mathrm{~nm}$ is 1.03 for the sample optimization in Fig. 2. This corresponds to a mere $36 \%$ transmittance at nadir, not including the effect of molecular scattering. Reflectances at $2250 \mathrm{~nm}$ were typically low, averaging about $5 \%$. According to Kaufman et al. (1997), the $410 \mathrm{~nm}$ reflectance would be one quarter of this, $1.25 \%$. This surface reflectance transmitted through the aerosol layer at nadir would only be about 0.5 in reflectance units, while the total unpolarized reflectance is typically between $15 \%$ and $20 \%$. Errors associated with the approximation of $410 \mathrm{~nm}$ reflectance would thus be suppressed in a similar manner. For this reason, one short wavelength band was included in the optimization vector $\mathbf{G}(\boldsymbol{x})$. Longer wavelength bands were not used because of the risk of sensitivity to inaccurate surface reflectance characterization, both due to higher surface reflectance values in the red and near-infrared, and lower surface-obscuring aerosol transmission.

Table 1 lists the model parameters, their units, and the a priori optimization values $\left(\boldsymbol{x}_{\mathrm{o}}\right)$. A priori values were selected using the boreal forest fire smoke properties in Dubovik et al. (2002), which were derived from systematic observations of sunphotometers in the Aerosol Robotic Network (AERONET). Parameters listed in italics in Table 1 are retrieved during optimization, while the others are fixed.

It has been suggested that the imaginary refractive index of some types of biomass burning smoke have a spectral dependence, specifically an increase in absorption (imaginary refractive index) in the blue and ultra-violet (Andreae and Gelencsér, 2006; Lewis et al., 2008; Russell et al., 2010; Bergstrom et al., 2010). Unfortunately, direct observations of smoke complex refractive indices are very limited. $\mathrm{Ab}$ sorption in smoke aerosols is typically associated with Black Carbon (BC) whose imaginary refractive index is spectrally flat. Organic Carbon (OC), which covers a wide range of species with varying chemical concentrations, is the source of absorption at short wavelengths (Kirchstetter et al., 2004). The relative contribution of $\mathrm{BC}$ and $\mathrm{OC}$ varies considerably
Table 1. Retrieved aerosol parameters and the initial values used in optimization. Parameters listed in italics are optimized during the retrieval, while all others are kept constant. a Refractive Index values have no spectral dependence. ${ }^{b}$ For optimizations that utilize data from the HSRL, the a priori number concentration is determined by the HSRL observations. ${ }^{\mathrm{c}}$ For optimizations that utilize data from the HSRL, the aerosol layer height is fixed by HSRL observations and not changed during optimization.

\begin{tabular}{|c|c|c|c|}
\hline Parameter & Symbol & Unit & a priori \\
\hline \multicolumn{4}{|c|}{ Fine mode parameters } \\
\hline Real refractive index ${ }^{a}$ & $\mathcal{R}\left(m_{\mathrm{f}}\right)$ & $\mathrm{n} / \mathrm{a}$ & 1.52 \\
\hline Imaginary refractive index ${ }^{a}$ & $\mathcal{I}\left(m_{\mathrm{f}}\right)$ & $\mathrm{n} / \mathrm{a}$ & 0.0094 \\
\hline Effective radius & $r_{\mathrm{e}, \mathrm{f}}$ & $\mu \mathrm{m}$ & 0.15 \\
\hline Effective variance & $v_{\mathrm{e}, \mathrm{f}}$ & $\mathrm{n} / \mathrm{a}$ & 0.20 \\
\hline Number concentration ${ }^{b}$ & $n_{\mathrm{f}}$ & mum $^{-2}$ & 5.5 \\
\hline
\end{tabular}

\begin{tabular}{llll}
\hline \multicolumn{4}{c}{ Coarse mode parameters } \\
\hline Real refractive index $^{\mathrm{a}}$ & $\mathcal{R}\left(m_{\mathrm{c}}\right)$ & $\mathrm{n} / \mathrm{a}$ & 1.52 \\
Imaginary refractive index $^{\mathrm{a}}$ & $\mathcal{I}\left(m_{\mathrm{c}}\right)$ & $\mathrm{n} / \mathrm{a}$ & 0.0094 \\
Effective radius $^{\text {Effective variance }}$ & $r_{\mathrm{e}, \mathrm{c}}$ & $\mu \mathrm{m}$ & 3.21 \\
Number concentration $^{\mathrm{b}}$ & $v_{\mathrm{e}, \mathrm{c}}$ & $\mathrm{n} / \mathrm{a}$ & 0.23 \\
\hline \multicolumn{5}{c}{ Other parameters $_{\mathrm{c}}$} & mum $^{-2}$ & 0.0001 \\
\hline Aerosol height $^{\mathrm{c}}$ & $h$ & $\mathrm{~m}$ & 5000 \\
\hline
\end{tabular}

depending on the fire type and smoke age. BC is usually more associated with hot, flaming fires, while OC is greater in cooler, smoldering fires. Since our smoke plume was created by young fires with many hotspots, we expect that $\mathrm{BC}$ will dominate. Initially we did include a retrieval parameter that allowed the refractive index to increase linearly (as wavelength decreases) for wavelengths less than $532 \mathrm{~nm}$. However, most of our retrievals converged to a solution with no imaginary refractive index spectral dependence. Segments that did converge with a spectral dependence typically had a large residual error. We therefore conclude that either an imaginary refractive index spectral dependence does not exist for this smoke, or we are not sensitive to it. We therefore used a spectrally flat imaginary refractive index in our retrievals.

To facilitate comparison of our results with data collected by other instruments, we computed a variety of other aerosol properties using the retrieved aerosol properties. These derived parameters are listed in Table 2, along with information about the method used to derive them if they are not byproducts of the forward model. Retrieved parameter uncertainty was determined from Eq. (12) as described above, and derived parameter uncertainty was calculated numerically as in Eq. (13). 
Table 2. Derived aerosol parameters. $\lambda$ is wavelength.

\begin{tabular}{llll}
\hline Parameter & Symbol & Unit & Calculation \\
\hline Scattering cross-section & $\sigma_{\mathrm{s}}(\lambda)$ & $\mu \mathrm{m}^{2}$ & model byproduct \\
Absorption cross-section & $\sigma_{\mathrm{a}}(\lambda)$ & $\mu \mathrm{m}^{2}$ & model byproduct \\
Extinction cross-section & $\sigma_{\mathrm{e}}(\lambda)$ & $\mu \mathrm{m}^{2}$ & $\sigma_{\mathrm{e}}(\lambda)=\sigma_{\mathrm{a}}(\lambda)+\sigma_{\mathrm{s}}(\lambda)$ \\
Asymmetry parameter & $g(\lambda)$ & $\mathrm{n} / \mathrm{a}$ & model byproduct \\
Aerosol optical thickness & $\tau(\lambda)$ & $\mathrm{n} / \mathrm{a}$ & $\tau(\lambda)=n \sigma_{\mathrm{e}}(\lambda)$ \\
Angström exponent & $\alpha$ & $\mathrm{n} / \mathrm{a}$ & $\operatorname{Slope~of~} \ln (\lambda) \operatorname{vs} \ln \left(\sigma_{\mathrm{e}}(\lambda)\right)$ \\
Single scattering albedo & $\varpi(\lambda)$ & $\mathrm{n} / \mathrm{a}$ & $\varpi(\lambda)=\sigma_{\mathrm{s}}(\lambda) / \sigma_{\mathrm{e}}(\lambda)$ \\
Phase function at backscatter & $P_{11}\left(\lambda, \Theta=180^{\circ}\right)$ & $\mathrm{n} / \mathrm{a}$ & $\operatorname{model~byproduct}$ \\
Backscatter extinction ratio & $S(\lambda)$ & $\mathrm{sr}$ & $4 \Pi /\left[\varpi(\lambda) P_{11}\left(\lambda, \Theta=180^{\circ}\right)\right]$ \\
\hline
\end{tabular}

\subsubsection{Atmospheric layer heights}

As discussed in Waquet et al. (2009), absorbing aerosol properties are difficult to retrieve without information about their vertical distribution. This paper is therefore intended to test how to best model absorbing aerosol vertical distribution. To do so, we performed optimizations with and without data supplied by the HSRL, and compare the results.

Retrievals performed without HSRL data modeled aerosols in a single, uniform layer attached to the ground. The top of the layer was allowed to vary as an optimization parameter. As listed in Table 1, the initial altitude was $5000 \mathrm{~m}$, while initial values for aerosol number concentrations were selected to replicate the mean optical depth for biomass burning aerosols as given by Dubovik et al. (2002).

Unlike traditional backscatter lidars, the HSRL has the ability to discriminate between aerosol and molecular backscatter in the $532 \mathrm{~nm}$ channel. This provides an independent estimation of aerosol extinction and backscatter coefficients, and means that the observed aerosol optical depth is directly estimated with no microphysical assumptions required. A more detailed description of this instrument can be found in Sect. 2.4.1. To find aerosol layer top and bottom heights, we took the derivative of the aerosol volume backscatter coefficient, $b$, after it had been weighted by the two pass atmospheric transmission (using the extinction coefficient, $k_{\mathrm{e}}$ ) from the specified altitude, $h$, to the aircraft altitude, $h_{\mathrm{a}}$ (Eq. 14). Arbitrary thresholds were set for the result, $\gamma(h)$, where absolute values above the threshold indicate an aerosol layer top or bottom.

$\gamma(h)=\frac{d}{d h}\left(b(h) e^{-2 \int_{h}^{h_{\mathrm{a}}} k_{\mathrm{e}}\left(h^{\prime}\right) d h^{\prime}}\right)$

Aerosol layer heights were fixed within the optimization, and aerosols were distributed evenly with respect to pressure throughout each layer. The results of this layer identification can be seen in the first panel of Fig. 3. Red dashed lines indicate the tops and bottoms of the pair of layers identified using Eq. 14. An additional piece of information from the
HSRL is the total column aerosol optical depth at $532 \mathrm{~nm}$. This was used to select a priori $n_{\mathrm{c}}$ and $n_{\mathrm{f}}$, which were distributed according to the aerosol optical depth in each layer. The relationship between $n$ and aerosol optical depth was determined by the extinction cross-section calculated by the forward model for initial values of refractive index and size. Ratios of aerosol optical depth for both modes between different layers were maintained throughout the optimization.

\subsection{Validation data}

Results of the optimization with and without HSRL data were compared to a variety of contemporaneous measurements by other instruments. The first comparison we made was between optimization results and HSRL observations of aerosol optical thickness, $\tau$, and the backscatter to extinction ratio, $S$, at $532 \mathrm{~nm}$. The former comparison is somewhat compromised by the fact that it was used to set the initial aerosol number concentration. However, since the initial values for size and complex refractive index are different than the retrieved values, the optical depth of a specified aerosol number concentration must also change. All of these values are unconstrained, so agreement between RSP and HSRL optical depth is by no means guaranteed by the choice of the initial value. In addition to comparisons with the HSRL, the B-200 flew in coordination with the NASA P-3 aircraft, which carried two instruments of interest to us. The AATS14 instrument provided the column aerosol optical thickness (above the aircraft) in fourteen narrow wavelength channels. The aerosol Ångström exponent, $\alpha$, was also calculated using these data by performing a linear regression in the log-log domain. The HiGEAR suite of in situ sampling instruments provided the aerosol absorption $\left(k_{\mathrm{a}}\right)$ and scattering $\left(k_{\mathrm{s}}\right)$ coefficients, from which the single scattering albedo, $\varpi$ is derived. HiGEAR instrument suite also measured aerosol size information, which we present as the effective radius, $r_{\mathrm{e}}$ and effective variance, $v_{\mathrm{e}}$. Details about the collection of these data and the motivation for their use to validate RSP aerosol property retrievals are described below. 


\subsubsection{HSRL}

The HSRL, as described above and in more detail in Hair et al. $(2001,2008)$ and Rogers et al. (2009) is a dual band (532 and $1064 \mathrm{~nm}$ ) lidar that was deployed along with the RSP on the B-200 aircraft. The HSRL uses an iodine cell with a narrow spectral absorption feature centered on the laser line at $532 \mathrm{~nm}$ to absorb radiation scattered by aerosols (close to the laser line) and transmit light scattered by molecules (Doppler shifted away from the laser line). Another channel is used to measure the light scattered by aerosols and molecules at $532 \mathrm{~nm}$, similar to the usual elastic backscatter lidar measurement. This capability means that the HSRL can distinguish molecular from aerosol backscatter without the microphysical assumptions that are required for regular lidars. At $1064 \mathrm{~nm}$, the typical lidar approach is used, although the $532 \mathrm{~nm}$ measurements can be used to constrain the derivation of backscatter profiles (Hair et al., 2008). The HSRL also observes the depolarization ratio, $d$, which is the ratio of the perpendicular (cross-polarized) to parallel polarized aerosol backscatter coefficient. This parameter provides a measure of the sphericity of the aerosols since is a unitless ratio. In the case of single scattering it is zero for spheres. During this scene, the HSRL observed particulate depolarization of about 0.05 , with is small enough that the aerosols can be treated as spheres (as they are in our radiative transfer model). The spherical assumption is reasonable for slightly aged smoke particles, which start as filaments and collapse into more compact shapes in the first few hours after creation (Abel et al., 2003; Reid and Hobbs, 1998; Liu et al., 2008).

\subsubsection{AATS-14}

The Ames Airborne Tracking Sunphotometer (AATS-14) is a fourteen channel $(354 \mathrm{~nm}$ to $2139 \mathrm{~nm})$ autonomous sun tracking sun photometer. It is mounted externally on the top of an aircraft, and provides above aircraft aerosol optical thickness by continuously tracking the direct solar beam. This is successful provided the solar disk is not obscured by clouds or interference from the aircraft body and that the aircraft angular motion does not exceed $6^{\circ}$ per second. Calibration is extremely stable, typically maintained within $1 \%$ over the course of about a year. The AATS-14 has been deployed on a variety of aircraft during field campaigns since 1996 (for example, Russell et al., 1999; Schmid et al., 2003, 2006; Redemann et al., 2005; Livingston et al., 2009). During ARCTAS, the AATS-14 was mounted on the P-3 aircraft, which flew under the B-200 at a low altitude (Shinozuka et al., 2011). AATS-14 should provide an excellent measure of the spectral dependence of aerosol optical depth. As we will see below (with the in situ instrument data), there are smoke related aerosols at the P-3 altitude, even if the total quantity of aerosols between the P-3 and the ground is much less than the quantity above. Thus, the column aerosol optical thickness that we observe with the RSP is at least as large as the values measured by the AATS-14, and should be slightly higher.

For validation purposes, we want to compare aerosol optical thickness at the same wavelength. The RSP optimization software can produce an optical thickness at any wavelength (with an extra radiative transfer model run with the final parameters at the specified wavelength), while the HSRL only provides an independent measure of column aerosol optical thickness at $532 \mathrm{~nm}$. This is not an AATS channel (the closest is $520 \mathrm{~nm}$ ), so AATS aerosol optical thickness at $532 \mathrm{~nm}$ was determined by fitting a second order polynomial to the spectra in the log-log domain. Uncertainty values were interpolated in the same manner.

\subsubsection{HiGEAR}

HiGEAR is a suite of instrumentation deployed by the University of Hawaii on the P-3. HiGEAR provided validation data in the form of absorbing and scattering coefficients (from which the Ångström exponent and single scattering albedo can be derived) and the aerosol particle size distribution. Some examples of results from previous field campaigns can be found in Clarke et al. (2007) and McNaughton et al. (2009). Shinozuka et al. (2011) integrated the in situ measurements over the vertical profiles flown during ARCTAS, and demonstrated that the resulting layer aerosol optical depth agrees with AATS-14 measurements within $3 \%$ or 0.02 .

The aerosol size distribution was determined by two instruments. The Long Differential Mobility Analyzer (LDMA) counts particles in the 0.01 to $0.5 \mu \mathrm{m}$ diameter range (Clarke et al., 1998). The LDMA maintains the aerosols at ambient temperature and pressure, at dry (less than $30 \%$ ) humidities. Particles in the 0.5 to $10 \mu \mathrm{m}$ range were measured by a TSI model 3321 aerodynamic particle sizer (APS) (McNaughton et al., 2007). Like the LDMA, the APS operates at ambient temperature and pressure at dry humidities. Effective radius and variance were calculated by fitting a log-normal distribution to the data and deriving the effective radius and variance values from the fit parameters (see Eq. 2.60 and the next page of discussion in Hansen and Travis, 1974). The log-normal distribution is

$n(r)=\frac{1}{r \sigma_{\mathrm{g}}(2 \pi)^{1 / 2}} e^{\frac{-(\ln r-\ln r \mathrm{~g})^{2}}{2 \sigma_{\mathrm{g}}^{2}}}$

where $r$ is the aerosol radius and $n(r)$ is the number density of aerosols at radius $r . r_{\mathrm{g}}$ and $\sigma_{\mathrm{g}}$ are the fit parameters, and are used to derive the effective radius, $r_{\mathrm{e}}$, and variance, $v_{\mathrm{e}}$, with

$r_{\mathrm{e}}=r_{\mathrm{g}}\left(1+v_{\mathrm{e}}\right)^{5 / 2}$

$v_{\mathrm{e}}=e^{\sigma_{\mathrm{g}}^{2}}-1$. 

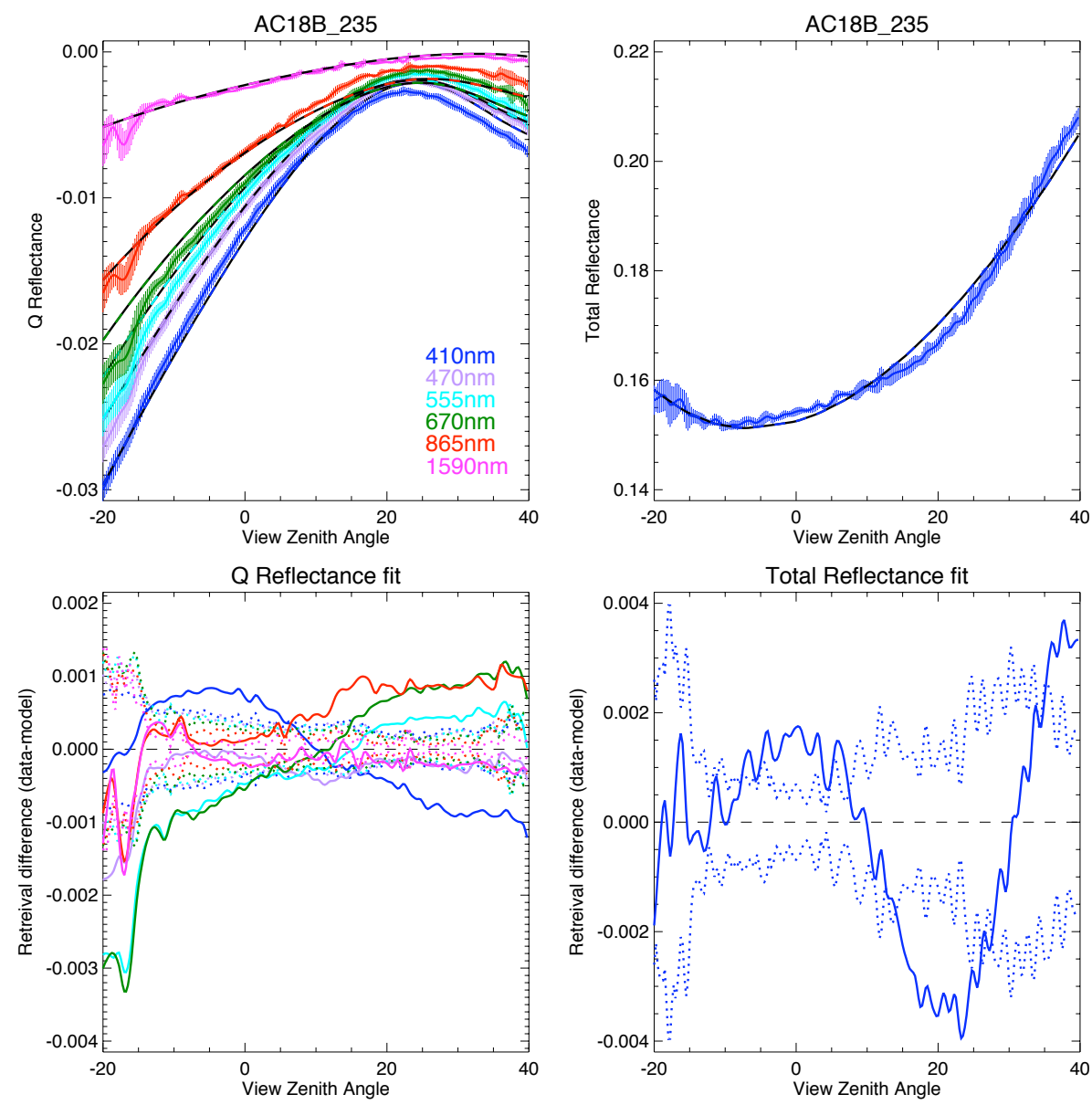

Fig. 2. Sample results from an optimization using HSRL data. In the top panels, measured reflectances, and their associated errors, are plotted with solid lines with respect to the view zenith angle. Model results are plotted with dashed lines. Negative view zenith angles indicate aircraft forward scan directions, while positive values represent aft observations. $R_{Q}$ is plotted on the left, while $R_{I}$ is on the right. The bottom panels display the measurement minus model residuals. Dotted lines in these panels indicate the total error associated with that observation. $410 \mathrm{mn}$ results are in blue, $470 \mathrm{~nm}$ in purple, $555 \mathrm{~nm}$ in cyan, $670 \mathrm{~nm}$ in green, $865 \mathrm{~nm}$ in red and $1590 \mathrm{~nm}$ in magenta.

This fitting was performed to avoid the noise sensitivity associated with direct computation of effective radius and variance (Eqs. 2.53 and 2.54 in Hansen and Travis, 1974), which are functions of the second, third and fourth moments of the size distribution, and therefore more prone to noise. Measurement uncertainty is the uncertainty associated with the fitting; observations with large uncertainty in either effective radius or variance indicate that the aerosol size distribution is not well represented by a log-normal distribution. Furthermore, fitting was performed with a bimodal size distribution (the total number concentration was the summation of two terms like that in Eq. 15). However, since the fine mode dominated the coarse mode to such a degree that the latter was difficult to even detect, subsequent comparisons of RSP and HiGEAR size distributions apply to the fine mode only.

Scattering and absorption coefficients are necessary to compute the Ångström exponent and single scattering albedo. Scattering coefficients were measured at 450 ,
550 and $700 \mathrm{~nm}$ by a TSI model 3563 nephelometer. Data were corrected for ambient temperature and pressure and relative humidities within the instrument were low, no more than $30 \%$. The Particle Soot Absorption Photometers (PSAP) measured the absorption coefficient at 470, 530 and $660 \mathrm{~nm}$. Measurements were corrected according to the methodology of Virkkula et al. (2005), and represent values at ambient temperature and pressure. The Single Scattering Albedo is calculated by combining both measurements with the ratio $\varpi=\sigma_{\mathrm{s}} /\left(\sigma_{\mathrm{s}}+\sigma_{\mathrm{a}}\right)$. This was done after interpolating the scattering and absorbing coefficients to $532 \mathrm{~nm}$. The nephelometer has a higher measurement frequency than the PSAP, so temporal averaging of the scattering coefficient was also required. 


\section{Results}

The primary goal of this paper was to test how observations from lidars such as the HSRL can be used to improve the analysis of RSP observations of optically thick smoke. We therefore performed a number of optimizations that incorporated HSRL data, then repeated them without that data and compared the results. This approach was taken so that the variability of retrieval results across the scene can be used to investigate the success of the method, and so the results can be compared in a statistical sense. The HSRL data that were incorporated into the RSP analysis included both an initial estimate of aerosol number concentration (derived from the HSRL optical depth at $532 \mathrm{~nm}$ and the initial guess of aerosol size and refractive index) and the aerosol vertical distribution defined as layers.

Table A1 in the appendix lists the time and location of the individual data segments. Of note is the large difference (between $20^{\circ}$ and $30^{\circ}$ ) between the aircraft heading and the actual ground track. This large "crab" angle is due to the high winds experienced by the B-200 because of the proximity to the polar jet that day. Since the RSP was therefore unable to scan in the plane of forward motion, the spatial extent of a data segment, when projected at the aerosol altitude, was larger in the cross track than the along track direction. This can be seen in Fig. 1, where the white polygons indicate the spatial extent of each data segment. For this reason, geometry data from the aircraft Inertial Monitoring Unit (IMU) was crucial. Unfortunately, we also found that there was occasionally some uncertainty associated with the IMU heading angle. A small correction to the heading angle was applied in order to ensure that the linear polarization angle remains parallel or perpendicular to the plane of scattering. This is what we expect for Fresnel (single interaction) polarized surface reflectance, so we use $2250 \mathrm{~nm}$ observations at scattering angles away from backscatter for this purpose, as those observations have the largest surface contribution to total reflectance.

Tables 3 and 4 contain the mean and median values for retrieved and derived parameters, respectively, for retrievals with and without HSRL data. Table 5 contains comparable results from the validation data. Both mean and median values are presented, as differences between them indicate the possibility that values are not normally distributed. This is the case for several of the parameters for retrievals without HSRL data, such as the effective variance $\left(v_{\mathrm{e}, \mathrm{f}}\right)$, fine mode number concentration $\left(n_{\mathrm{f}}\right)$, and scattering and extinction cross-sections $\left(\sigma_{\mathrm{s}}\right.$ and $\left.\sigma_{\mathrm{e}}\right)$. Since equivalent parameters measured by in situ instrumentation do not indicate a nonnormal distribution, this is the first indication that the retrievals performed without the HSRL may not be successful.

Figure 3 shows latitude indexed comparisons between RSP, HSRL, AATS and HiGEAR data, essentially the results as the aircraft flew through or above the smoke plume. Latitude was used as the reference because of the slight temporal
Table 3. Directly retrieved aerosol parameters. The mean and median are calculated for the set of optimizations. Uncertainties (denoted \pm ) are the median value returned by the optimization routine. Ratios are the standard deviation of the set of optimization results divided by the median optimization uncertainty.

\begin{tabular}{llllll}
\hline \multirow{2}{*}{ Parameter } & \multicolumn{2}{c}{ without HSRL } & & \multicolumn{2}{c}{ with HSRL } \\
\cline { 2 - 3 } \cline { 5 - 6 } & median & mean & & median & mean \\
\hline $\mathcal{R}\left(m_{\mathrm{f}}\right)$ & 1.57 & $1.55 \pm 0.075$ & & 1.44 & $1.45 \pm 0.054$ \\
$\mathcal{I}\left(m_{\mathrm{f}}\right)$ & 0.015 & $0.016 \pm 0.0064$ & & 0.005 & $0.005 \pm 0.0036$ \\
$r_{\mathrm{e}, \mathrm{f}}$ & 0.10 & $0.11 \pm 0.012$ & & 0.14 & $0.14 \pm 0.018$ \\
$v_{\mathrm{e}, \mathrm{f}}$ & 0.38 & $0.32 \pm 0.049$ & & 0.23 & $0.24 \pm 0.048$ \\
$n_{\mathrm{f}}$ & 82.25 & $61.74 \pm 0.182$ & & 14.27 & $17.04 \pm 0.111$ \\
$n_{\mathrm{c}}$ & 0.0001 & $0.0001 \pm 0.0020$ & & 0.0009 & $0.0008 \pm 0.0020$ \\
$h$ & 5475 & $5457 \pm 0.004$ & & & \\
\hline
\end{tabular}

difference between the B-200 and P-3 aircraft. The aircraft were traveling generally to the south, which in these plots is from left to right. HSRL data are the source of the imagery in each plot. The top panel is the aerosol backscatter coefficient at $532 \mathrm{~nm}\left(\mathrm{~km}^{-1} \mathrm{sr}^{-1}\right)$, which clearly shows elevated layers of aerosols at 3 to $4 \mathrm{~km}$. While most of the backscatter in the profile occurs at the elevated level, the presence of backscatter below that layer indicates that aerosols are distributed down to the surface. The dashed white line overlay in this plot is the top of the aerosol layer as retrieved from RSP data when HSRL data are not utilized. Clearly, this value is inconsistent, and rarely matches HSRL observations. Red line overlays indicate the layers derived from HSRL data using Eq. (14), while the orange dashed line near the bottom of the panel indicates the P-3 altitude (and thus the altitude of AATS and HiGEAR observations).

Our validation rests on several assumptions about the vertical distribution of aerosols that we acknowledge are somewhat contradictory. While these contradictions may physically exist, we believe that their radiative impacts are small enough so that they may be neglected. These assumptions are:

1. the P-3 aircraft was flying in aerosols with the same properties as observed from above by the RSP on the B200, so that HiGEAR observations provide a valid test of RSP retrieval results,

2. the P-3 is flying under a sufficiently large portion of the column aerosol burden that AATS optical thickness can be compared to RSP retrieved results,

3. aerosols in the direct solar beam measured by the upward looking AATS on the P-3 are the same as those observed by the downward viewing RSP on the B-200, and

4. that the temporal difference between the P-3 and B-200 observations are minimal. 

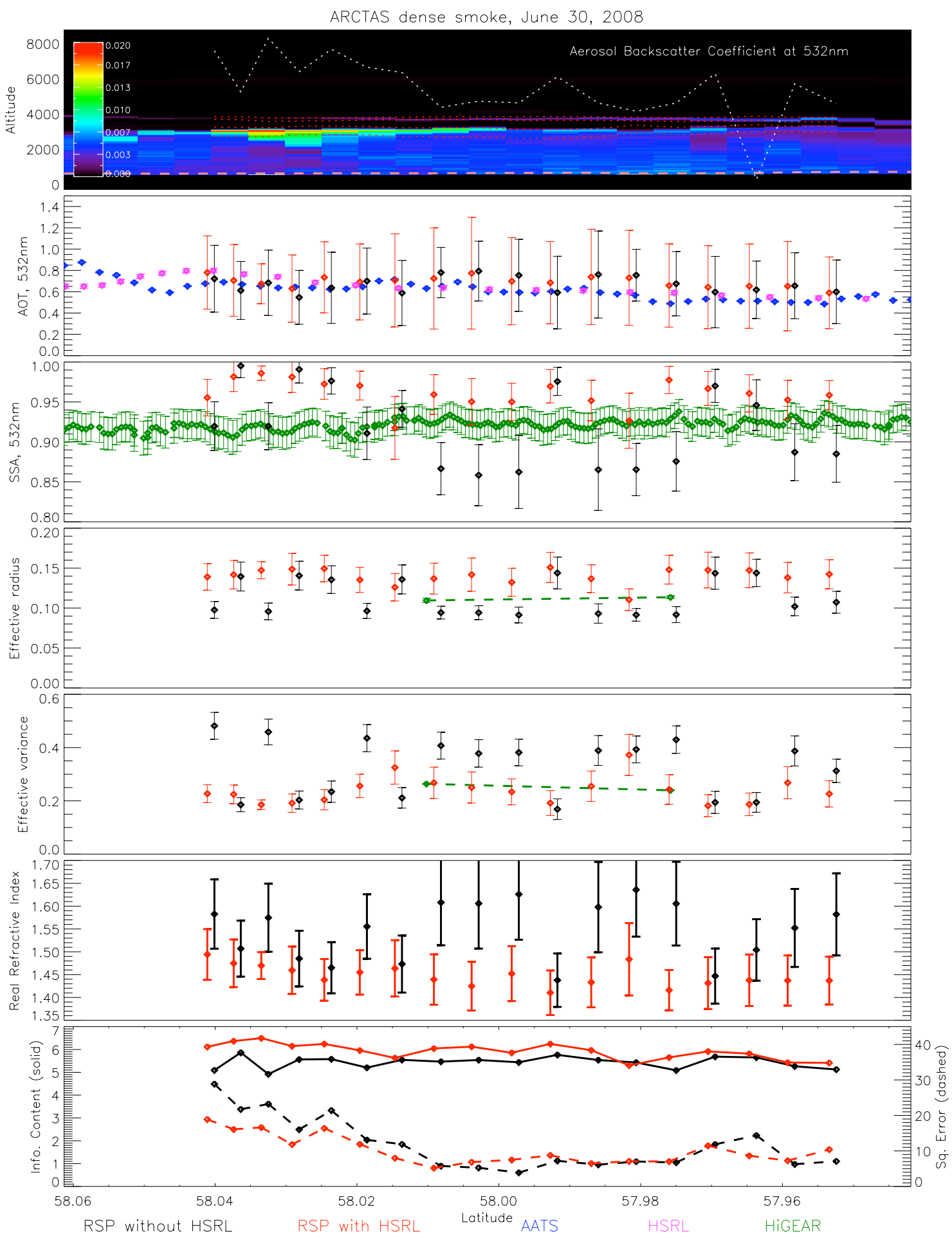

Fig. 3. RSP, HSRL, AATS and HiGEAR data are plotted with respect to latitude (aircraft were flying to the South). The top panel shows the HSRL aerosol backscatter coefficient at $532 \mathrm{~nm}$. The dashed white line is the retrieved aerosol layer height for RSP observations that did not include HSRL data. Dashed red lines indicate the HSRL determined aerosol layer heights used for RSP retrievals that used HSRL data. The orange dashed line indicates the altitude of the P-3 aircraft, which carried the AATS and HiGEAR instruments. The second panel is the total aerosol optical thickness at $532 \mathrm{~nm}$ for RSP retrievals without HSRL data (black), RSP retrievals with HSRL data (red), AATS (blue) and HSRL (magenta). That color scheme is maintained for the rest of the panels, with green indicating HiGEAR data in the third, fourth and fifth panels (Single Scattering Albedo, Effective Radius and Effective Variance, respectively). The sixth panel, with real refractive index, contains RSP data alone, indicating the validation difficulty of this parameter. Finally, the bottom panel is the information content (solid lines) and squared retrieval error (dashed lines) for the two RSP optimization methods. 
The HSRL data provide some indication as to the validity of these assumptions. For example, the HSRL extinction to backscatter ratio at $532 \mathrm{~nm}$ is nearly uniform (about $50 \mathrm{sr}$ ) within the plume, indicating that the aerosol optical properties, at least as they are expressed in that ratio, are vertically consistent. Furthermore, the total optical depth from HSRL and AATS are also quite similar (the median values differ by 0.033 at $532 \mathrm{~nm}$ ), which means that the AATS is observing a significant portion of the total aerosol column. At the solar zenith angle for our scene, the horizontal distance at the top of the aerosol layer between a zenith view from the P-3 and where the direct solar beam illuminating the P-3 enters the layer is on the order of two kilometers. Since the spatial resolution of a single scan at aerosol layer height is $65 \mathrm{~m}$ (see Sect. 2.1), and given that aircraft crab angles enlarge the spatial resolution in the cross track direction (see earlier in this section and the white sample polygons in Fig. 1), we can expect that AATS observations are physically close to RSP and HSRL observations.

Another assumption we make is that spheres are an appropriate geometric model for scattering by aerosols. We are confident that this is the case, since the HSRL observes depolarization ratios of about 0.05 (at $532 \mathrm{~nm}$ ) throughout the column, indicating that the aerosols can be treated optically as spheres (Hair et al., 2008).

Comparisons between RSP, AATS, HSRL and HiGEAR data are shown in the rest of the panels in Fig. 3. In each panel, RSP optimizations without HSRL data are in black, while optimizations using HSRL data are in red, and are staggered slightly with respect to latitude to aid visualization. AATS data are presented in blue, HSRL data in cyan, and HiGEAR data in green.

While this will be covered in more detail in Sect. 4, it is clear in Fig. 3 that the RSP retrievals without HSRL data are converging to two, significantly different, types of solutions. The first solution, which is similar to what is retrieved from RSP when HSRL data are used, involves low absorption and narrow size distribution aerosols, with real refractive index values less than 1.55 . This agrees with results from the HiGEAR data for single scattering albedo and fine mode effective variance, and to a lesser degree effective radius. A second solution, retrieved only when the RSP is not using HSRL data, are aerosols that are very absorbing, very small, with large effective variances and real refractive indices. Since the results of this second type of solution do not agree with HiGEAR, we assume that the optimization has found a false minimum in the cost function representing aerosols that may not be physically realistic but are optically a reasonable match to the RSP observations. Presumably, this false minima is not found when the optimization uses HSRL data because those optimizations are started with a physically realistic fine mode number concentration. However, despite their size and refractive index differences, the aerosol optical thicknesses of both states are quite similar and match HSRL and AATS observations of spectral optical

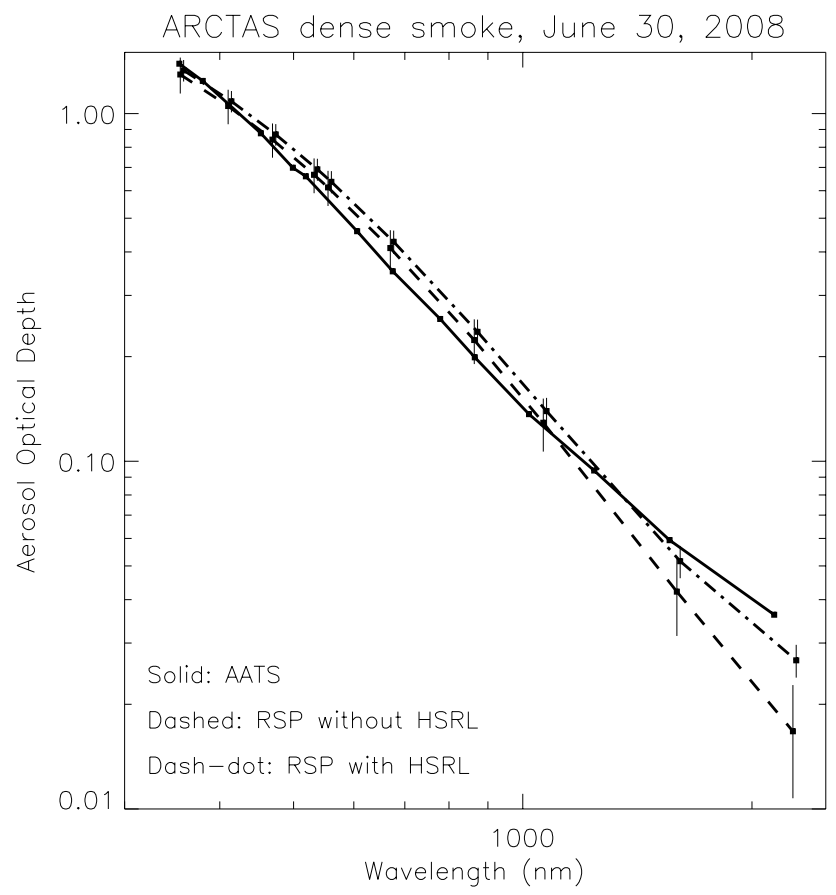

Fig. 4. Here we compare spectrally dependent aerosol optical thicknesses for AATS (solid) and RSP retrievals with and without HSRL data (dash-dot and dashed, respectively). Values are the geometric mean over the time and space shown in Fig. 3. Vertical lines indicate one standard deviation of the retrieval values in the region shown in Fig. 3, and have been offset with respect to the $\mathrm{x}$-axis slightly to ease visibility. Ångström exponents calculated within the $400 \mathrm{~nm}-$ $1000 \mathrm{~nm}$ range are $\alpha=2.35$ for RSP retrievals without HSRL data, $\alpha=2.53$ for RSP retrievals with HSRL data, and $\alpha=2.11$ for AATS

depth extremely well (see Fig. 4) . Optical depth retrievals do therefore appear to be robust against the uncertainties caused by multiple minima in the measurement cost function.

The bottom panel of Fig. 3 contains two measures of optimization success. Solid lines are the Shannon information content, $H_{\mathrm{s}}$, in parameter space as defined in Rodgers (2000) as

$H_{\mathrm{S}}=\frac{1}{2} \ln \left|\left(\mathbf{J}^{T} \mathbf{C}_{T}^{-1} \mathbf{J}+\mathbf{C}_{\mathrm{a}}^{-1}\right) \mathbf{C}_{\mathrm{a}}\right|$.

The information content represents the decrease in uncertainty following optimization, or equivalently the reduction in entropy. It is directly related to the volume of uncertainty for a given confidence level before and after the measurement process. Uncertainty prior to optimization is expressed by the a priori error covariance matrix, $\mathbf{C}_{\mathrm{a}}$, while the uncertainty following optimization is the error covariance matrix, $\mathbf{C}_{T}$ projected into state space using the Jacobian matrix. The solid lines in the bottom panel of Fig. 3 are this information content, which is slightly larger for retrievals using HSRL data during optimization compared to retrievals without HSRL data. Alternatively, optimization success can be expressed in observation space by the final value of the cost 
function as defined in Eq. (2) and plotted as dashed lines in Fig. 3. Like the information content, the final cost function value is slightly worse for optimizations performed without HSRL data, but does not indicate a convergence failure.

Figure 4 presents the mean spectral aerosol optical thickness from the AATS instrument compared to both types of RSP optimization results. All three are nearly identical (RSP without HSRL $\alpha=2.35$, RSP with HSRL $\alpha=2.53$, and AATS $\alpha=2.11$ ), with the exception of the of the very longest wavelengths, where optical thickness values are extremely low. This further illustrates how the spectral optical thickness is not affected by the divergent states retrieved with and without HSRL data.

\section{Discussion}

The primary goal of this paper is an investigation of the utility of lidar data in constraining and improving aerosol property retrievals with the RSP. First, we want to determine if the retrieved aerosol properties, when using HSRL data, are at least representative of boreal forest fire smoke. This appears to be the case. Comparisons with the ground sun photometer derived climatologies in Dubovik et al. (2002) show that our results are consistent with the boreal forest biomass burning class. Of course, this was also the source of the initial optimization values, so this comparison is only meaningful in the sense that it shows the results did not stray far from their original values. Unfortunately, there are few observations, other than AERONET, of boreal forest fire smoke that simultaneously retrieve refractive index, size and concentration. One additional source is the three wavelength lidar observations of Müller et al. (2005), who studied boreal forest fire smoke transported long distances from Canada to Germany. Complex refractive index and single scattering albedo both are consistent with our results. However, Müller et al. (2005) finds significantly larger aerosols, with an effective radius of $0.36 \pm 0.05 \mu \mathrm{m}$ for the entire size distribution, compared to our $0.14 \pm 0.02 \mu \mathrm{m}$ for the fine mode and $0.22 \mu \mathrm{m}$ for the entire size distribution for retrievals that use HSRL data as a constraint. One explanation for this difference is the growth associated with smoke aerosol aging (Reid et al., 1998; Müller et al., 2007), as our aerosols are much younger than those transported across the Atlantic to Europe. While few measurements of refractive index exist that are more accurate than the uncertainties in our retrievals, there are many measurements of single scattering albedo, which is closely related to the imaginary refractive index. Our value of 0.96 (at $532 \mathrm{~nm}$ ) is somewhat high compared to tables in the review by Reid et al. (2005a), indicating a low level of absorption for smoke aerosols. Boreal forest fires are known to produce less absorbing aerosols, and indeed the "likely optical properties" for "Temperate/Boreal Forest Aged" aerosols in Reid et al. (2005a) agree within uncertainties, with a value of $0.915 \pm 0.05$. Boreal forest single
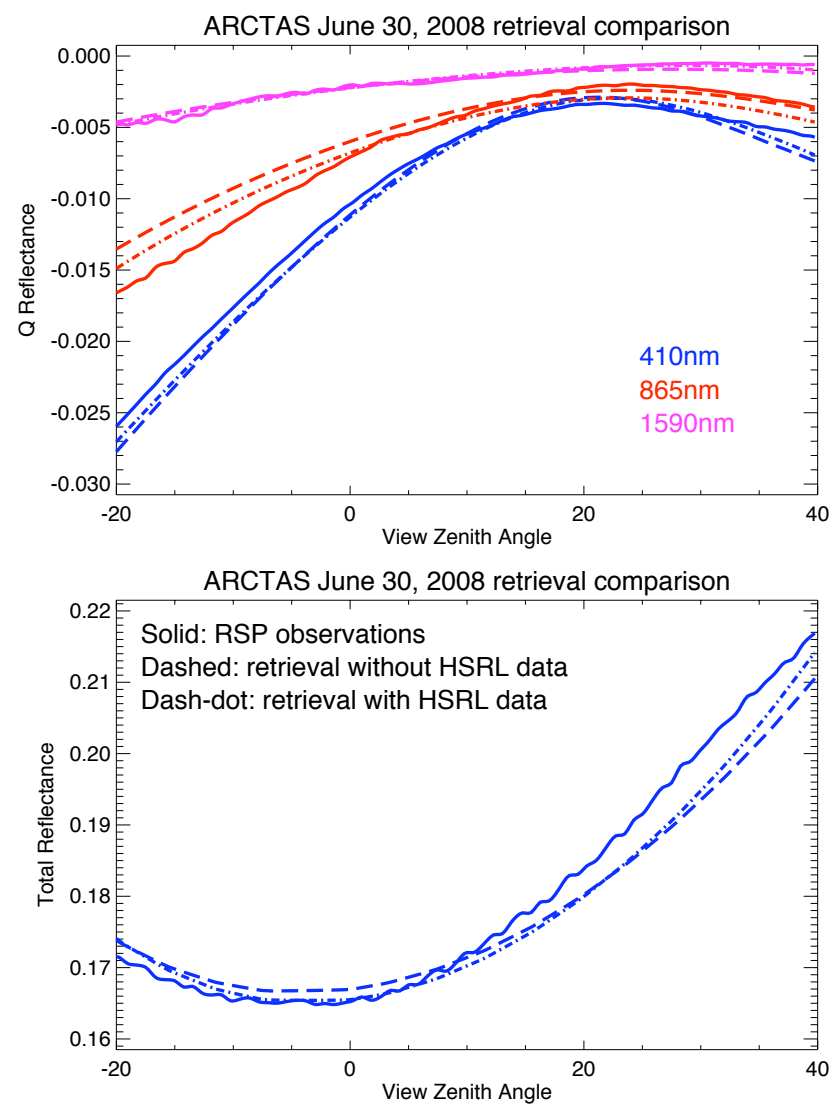

Fig. 5. These plots show results from a successful optimization utilizing HSRL data (dash-dot) compared to an unsuccessful optimization performed without HSRL data (dashed). This segment is the third from the left in Fig. 3, and RSP observed reflectances are plotted with solid lines. For clarity, the 470, 555 and $670 \mathrm{~nm}$ bands are omitted, although they show a similar situation: optimization retrieved reflectances are quite similar for both cases.

scattering albedo at $440 \mathrm{~nm}$ is $0.94 \pm 0.02$ for AERONET observations from Dubovik et al. (2002), while Eck et al. (2009) found average values at $440 \mathrm{~nm}$ of about 0.96 .

RSP results are compared to in situ observations of the smoke plume in Table 5, and Figs. 3, 4, 5, and 6. Optical thickness retrievals, both with and without HSRL data, compare well with HSRL column and AATS observations. Furthermore, the optical thickness spectral dependence is also well retrieved, as can be seen in Fig. 4. There is some difference at the longest wavelengths, but the magnitude of the optical depth at those wavelengths is so small that the estimates agree within measurement uncertainty. The only surprising aspect of the aerosol optical depth comparisons is the large RSP retrieval uncertainties (this will be discussed more below). "Successful" RSP retrievals (we will use this term to describe retrievals that used HSRL data and the retrievals without HSRL data that found nearly identical parameters) of single scattering albedo $(\varpi=0.960)$ are higher than HiGEAR observations (which have a $\varpi$ equal 
Table 4. Derived aerosol parameters. The mean and median are calculated for the set of optimizations. Uncertainties (denoted \pm ) are the median value returned by the optimization routine. Optical thickness $(\tau)$, scattering, absorption and extinction cross-sections $\left(\sigma_{\mathrm{s}}, \sigma_{\mathrm{a}}\right.$ and $\left.\sigma_{\mathrm{e}}\right)$, and single scattering albedo $(\varpi)$, are all expressed at $532 \mathrm{~nm}$.

\begin{tabular}{llllll}
\hline \multirow{2}{*}{ Parameter } & \multicolumn{2}{c}{ without HSRL } & & \multicolumn{2}{c}{ with HSRL } \\
\cline { 2 - 3 } \cline { 5 - 6 } & median & mean & & median & mean \\
\hline$\sigma_{\mathrm{S}}$ & 0.008 & $0.019 \pm 0.0044$ & & 0.033 & $0.032 \pm 0.0196$ \\
$\sigma_{\mathrm{a}}$ & 0.0010 & $0.0010 \pm 0.00052$ & & 0.0011 & $0.0010 \pm 0.00093$ \\
$\sigma_{\mathrm{e}}$ & 0.009 & $0.020 \pm 0.0048$ & & 0.034 & $0.033 \pm 0.0200$ \\
$\tau$ & 0.666 & $0.671 \pm 0.3038$ & & 0.695 & $0.693 \pm 0.3903$ \\
$\alpha$ & 2.35 & $2.43 \pm 0.204$ & & 2.53 & $2.52 \pm 0.258$ \\
$\varpi$ & 0.915 & $0.917 \pm 0.0318$ & & 0.960 & $0.960 \pm 0.0210$ \\
\hline
\end{tabular}

to 0.922). "Unsuccessful" RSP retrievals of single scattering albedo (those performed without the aid of HSRL data that are lower than "successful" RSP retrievals) are lower $(\varpi=0.915)$ and generally have larger uncertainties. Comparisons to HiGEAR observations for size distribution appear reasonable for "successful" RSP retrievals, with slightly larger effective radii and comparable effective variance values. "Unsuccessful" RSP retrievals have smaller effective radii, and much larger effective variance values than HiGEAR observations. Agreement for effective radius and variance were within uncertainties for both "successful" and "unsuccessful" retrievals, although it should be noted that HiGEAR uncertainty values are rather large. This is most likely related to the deviation of the actual size distribution from the log normal function to which we are fitting. In Fig. 6 we show the size distribution for a "successful" and "unsuccessful" RSP retrieval (Scan 170 in Table A1) compared to the closest HiGEAR observation. While this will be discussed in more detail below, it is notable that all three distributions are very similar in the $0.1-0.6 \mu \mathrm{m}$ range. "Unsuccessful" retrievals have an excess of small particles and the "successful" retrievals have a deficit of small particles compared to the HiGEAR size distribution. Finally, we should note that we do not have in situ observations of the real refractive index for comparison. As mentioned above, "successful" retrievals have refractive indexes that are similar to published boreal forest fire smoke values, although methods used to determine those published values have large uncertainty. "Unsuccessful" retrievals have much larger values that could possibly be associated with smoke particles containing significant amounts of Black Carbon (which would be consistent with the larger absorption of these retrievals). Our hypothesis that this is not physically the case is based upon the larger (complex) refractive index uncertainty of these retrievals and their physically unrealistic size distribution and single scattering albedo when compared to HiGEAR observations.

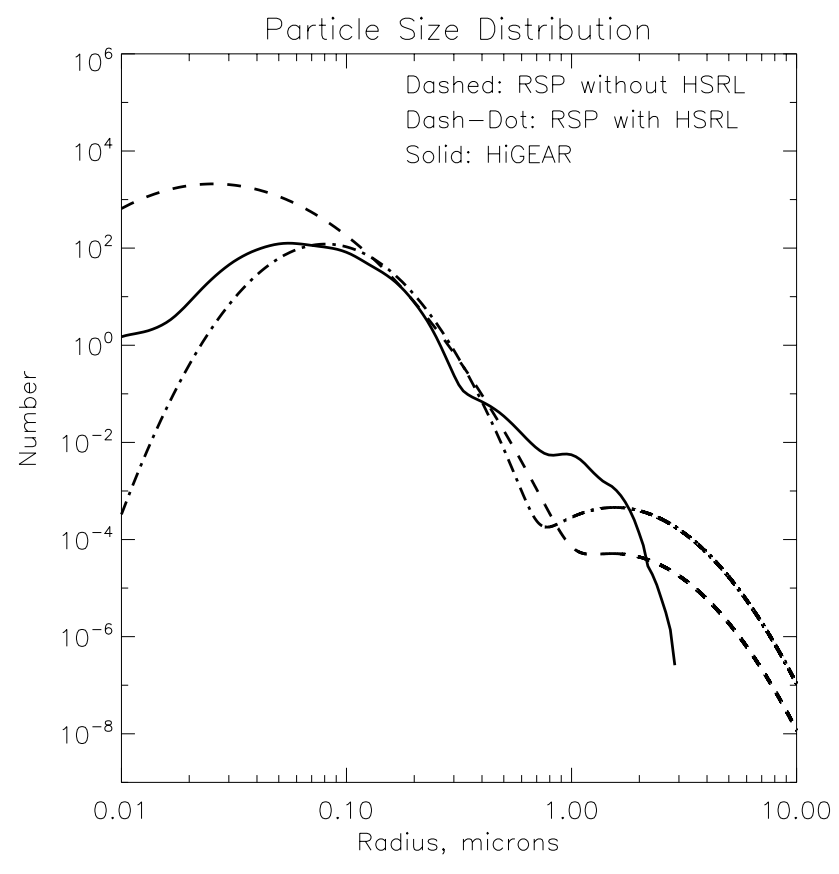

Fig. 6. This plot presents the retrieved and observed size distributions for the segment in Fig. 5. RSP results for a failed optimization without HSRL have dashed lines, RSP results for a successful optimization using HSRL data are represented as dash-dots, and the closest HiGEAR size distribution has a solid line. Because of the differences in sampling area, the HiGEAR data were normalized to the successful RSP size distribution.

The use of lidar data from the HSRL did improve RSP retrievals, but not in the way we anticipated. We had expected that an appropriate vertical distribution of aerosols would create retrievals that match in situ observations better and reduce their uncertainties. While retrievals utilizing HSRL data are reasonable, about half of the retrievals performed without HSRL data converged to nearly the same solution with equivalent uncertainties (what we call "successful" retrievals above). However, the other half of retrievals without HSRL data converged to an alternate solution that, while physically possible, is less consistent with in situ observations and has higher retrieval uncertainties (what we deem to be "unsuccessful" retrievals). This appears to happen not because of an inappropriate vertical distribution (otherwise the "successful" retrievals performed without HSRL data would not be so similar to those with HSRL data), but because of the initial values used to initiate the Levenberg-Marquardt iteration. Generally, the selection of inital parameter values is straightforward if there are clues to the type of aerosols present in the scene. In our case, the aerosols are obviously boreal forest fire smoke, so we used the climatology for this type from Dubovik et al. (2002). Dubovik et al. (2002) do provide mean values of aerosol optical thickness (from which number concentration can be derived if the extinction crosssection is known), but the range of reported values is so large 
Table 5. Retrieved aerosol results for validation data. The mean and median are calculated for the set of optimizations. Uncertainties (denoted \pm ) are the median value returned by the optimization routine. Optical thickness $(\tau)$, single scattering albedo $(\varpi)$ and the backscatter to extinction ratio $(S)$ are expressed at $532 \mathrm{~nm}$.

\begin{tabular}{lll}
\hline Parameter & median & mean \\
\hline AATS $\tau$ & 0.617 & $0.614 \pm 0.0051$ \\
HSRL $\tau$ & 0.650 & $0.658 \pm 0.0200$ \\
RSP without HSRL $\tau$ & 0.666 & $0.671 \pm 0.3038$ \\
RSP with HSRL $\tau$ & 0.695 & $0.693 \pm 0.3903$ \\
\hline HiGEAR $\varpi$ & 0.922 & $0.921 \pm 0.0181$ \\
RSP without HSRL $\varpi$ & 0.915 & $0.917 \pm 0.0318$ \\
RSP with HSRL $\varpi$ & 0.960 & $0.960 \pm 0.0210$ \\
\hline HiGEAR $r_{\mathrm{e}, \mathrm{f}}$ & 0.112 & $0.112 \pm 0.0022$ \\
RSP without HSRL $r_{\mathrm{e}, \mathrm{f}}$ & 0.100 & $0.113 \pm 0.0118$ \\
RSP with HSRL $r_{\mathrm{e}, \mathrm{f}}$ & 0.142 & $0.140 \pm 0.0180$ \\
\hline HiGEAR $v_{\mathrm{e}, \mathrm{f}}$ & 0.252 & $0.252 \pm 0.0011$ \\
RSP without HSRL $v_{\mathrm{e}, \mathrm{f}}$ & 0.380 & $0.325 \pm 0.0492$ \\
RSP with HSRL $v_{\mathrm{e}, \mathrm{f}}$ & 0.230 & $0.238 \pm 0.0476$ \\
\hline HSRL $S$ & 49.4 & $49.5 \pm 4.5$ \\
RSP without HSRL $S$ & 54.9 & $57.2 \pm 8.6$ \\
RSP with HSRL $S$ & 66.0 & $65.7 \pm 12.1$ \\
\hline
\end{tabular}

that the aerosol number concentration is unconstrained by climatology. This is because it is not an inherent quality of the aerosol type itself. Furthermore, aerosol optical thickness is log-normally, rather than normally, distributed (O'Neill et al., 2000; Knobelspiesse et al., 2004), which means there is the possibility of very large concentrations that are far from the arithmetic mean. The selection of the initial value for the number concentration is therefore quite difficult. As we see here, an incorrect selection can converge to a physically feasible local minimum in the cost function that is noticeably different from the minima that agrees with in situ observations. The HSRL data, then, were important because it was used to choose the initial number concentration, and the result was convergence to a much more consistent retrieval with lower uncertainties.

We next want to address why the specific set of parameters retrieved in "unsuccessful" cases matched RSP observations so well. As we can see from the dashed lines in the bottom panel of Fig. 3, there is no obvious difference between the squared error for "successful" and "unsuccessful" retrievals. Both cases are capable of matching RSP observations well, so in this case fit quality does not distinguish between "successful" and "unsuccessful" retrievals. To illustrate, Fig. 5 shows the match of model results to RSP observations for segment 170 (see Table A1). Retrieval results without HSRL data were 'unsuccessful' in this segment, but their simulated total and polarized reflectances (dashed lines) are not dramatically different than those for a "successful" retrieval using HSRL data (dash-dot lines; RSP data are solid lines). It appears that both "successful" and "unsuccessful" retrievals are similar in the observation space, $\boldsymbol{Y}$. Figure 6 presents an interesting clue as to why this may be the case. In this plot, the retrieved size distributions for segment 170 are shown, along with the closest HiGEAR observation. There are considerable differences between the retrieved and observed size distributions for very small and coarse mode aerosols, but a striking similarity for radii between 0.1 and $0.6 \mu \mathrm{m}$. It appears that this size range is the optically relevant portion of the size distribution, and that the optimization technique faithfully matched those sizes, albeit in two very different ways. Another possibility is that multiple scattering effects (recall that this is a scene with a large optical thickness and thus significant multiple scattering) could mask differences between the two aerosol states. Figure 7 presents the single scattering total (left) and polarized (right) phase functions at $532 \mathrm{~nm}$ for the same segment with (solid) and without (dashed) HSRL data. The full phase function is plotted in the top row, while a zoom of the scattering angles we observe is in the bottom row. Clearly, there is a difference in single scattering properties between the two states, and this appears to be masked by multiple scattering (as we can see in Fig. 3). The lower single scattering albedo for the "unsuccessful" case must be compensating for the larger phase function magnitude when multiple scattering is considered, since the angular dependence over the range of observation angles is similar for both "successful" and "unsuccessful" phase functions. Indeed, the high absorption retrieved in the "unsuccessful" cases can be seen as a symptom of an incorrect size distribution, as that absorption is needed to account for the larger amount of scattering by the smaller size distribution at the observed scattering angles.

Differences between "successful" and "unsuccessful" retrievals imply that there is a trade-off between the number of small particles (less than $0.1 \mu \mathrm{m}$ ) and complex refractive index that is weakly constrained by the observations. Both cases represent minima that are within the range of plausible aerosol properties, so success is highly dependent on initial value. This situation appears similar to results from an analysis of simulated ground based estimates of polarized sky observations (Cairns et al., 1997). Simulated retrievals were performed for haze and bimodal aerosol size distributions. Haze effective radius was correctly retrieved, but there was a substantial overestimate of small particles. The retrieved real refractive index for this case was about 0.1 larger than it should be, and the effective radius was quite different. These errors are similar to our 'unsuccessful' case, especially since both the simulation and the retrieval size distributions were similar in the 0.1-1.0 $\mu \mathrm{m}$ range (see Fig. 5b in Cairns et al., 1997). Furthermore, differences between the single scattering phase functions were masked by multiple scattering when modeling an optical depth of 0.5 . 

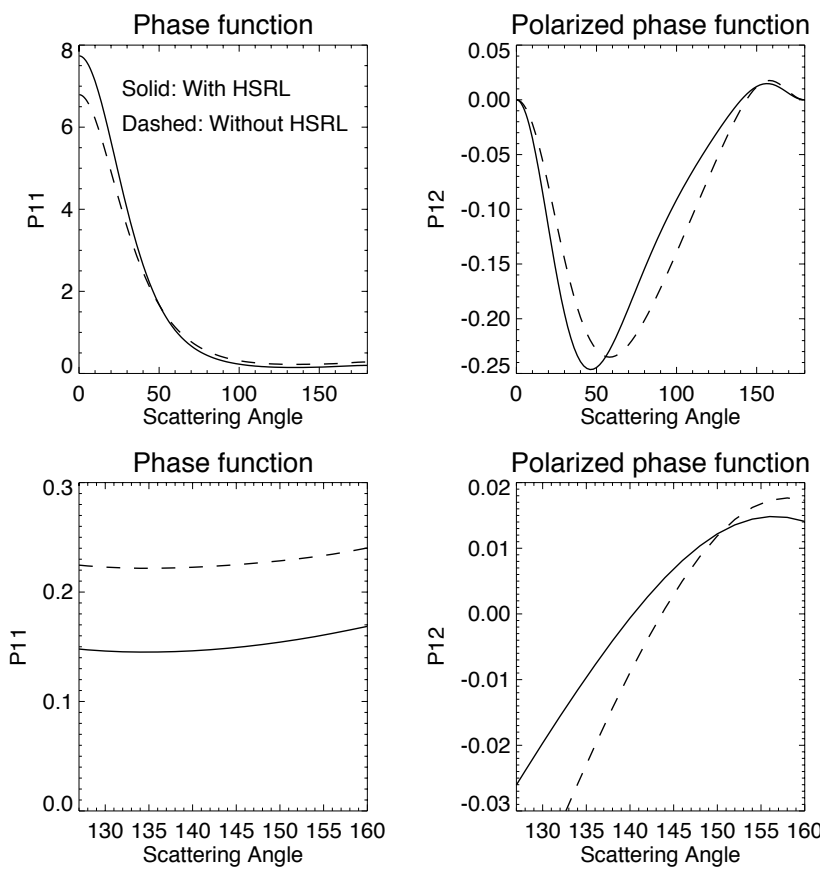

Fig. 7. These plots show the phase functions at $532 \mathrm{~nm}$ of the fine mode aerosols for the segment in Fig. 5. Successful optimization results using HSRL data are shown with solid lines, while unsuccessful optimization results performed without HSRL data have dashed lines. Plots in the left column are the total (unpolarized) phase function, while plots in the right column are the polarized phase function. Figures in the top and bottom rows show the same quantities, although the bottom rows have been zoomed to a scattering angle range that was observed by the RSP in that segment.

This illustrates a weakness in the ability to retrieve the number of aerosols whose size is large enough to activate as a cloud condensation nuclei $(\mathrm{CCN})$ at higher supersaturations (roughly 0.03 to $0.07 \mu \mathrm{m}$ ). The number of aerosols in this size range is important if we are to understand aerosol indirect effects on clouds, since Dusek et al. (2006) found that cloud nucleation is more determined by the aerosol size distribution than its chemical composition. However, aerosol plumes with number concentrations and opacity as thick as we have observed may also have difficulty nucleating in an updraft because of the strong competition for water vapor between particles. Sensitivity to CCN sized aerosols is a topic of ongoing interest that needs to be addressed for polarimetric remote sensing at lower aerosol optical depths, where concentrations of smaller particles may be important for the creation of cloud droplets.

The large uncertainty in the retrieved aerosol optical thickness must also be discussed. Aerosol optical depth uncertainty for both "successful" and "unsuccessful" retrievals is typically about $50 \%$, which in an absolute sense has an average value 0.39 at $532 \mathrm{~nm}$ for retrievals that use HSRL data. To find the source of this error we break down the components of the summation in Eq. (13), which are displayed in
Table 6. Error components for fine mode optical thickness at $532 \mathrm{~nm}$ for the segment 170 retrieval with HSRL data and solar zenith angle error assessed at $0.5^{\circ}$. These are the elements within the summations in Eq. (13).

\begin{tabular}{lcrrrr}
\hline & $n_{\mathrm{f}}$ & $\mathcal{R}\left(m_{\mathrm{f}}\right)$ & $\mathcal{I}\left(m_{\mathrm{f}}\right)$ & $r_{\mathrm{e}, \mathrm{f}}$ & $v_{\mathrm{e}, \mathrm{f}}$ \\
\hline$n_{\mathrm{f}}$ & 0.0000 & 0.0000 & 0.0000 & 0.0000 & 0.0000 \\
$\mathcal{R}\left(m_{\mathrm{f}}\right)$ & 0.0000 & 0.0143 & -0.0002 & -0.0379 & -0.0100 \\
$\mathcal{I}\left(m_{\mathrm{f}}\right)$ & 0.0000 & -0.0002 & 0.0000 & 0.0007 & -0.0001 \\
$r_{\mathrm{e}, \mathrm{f}}$ & 0.0000 & -0.0379 & 0.0007 & 0.1074 & 0.0272 \\
$v_{\mathrm{e}, \mathrm{f}}$ & 0.0000 & -0.0100 & -0.0001 & 0.0272 & 0.0141 \\
\hline
\end{tabular}

Table 6. Uncertainties in effective radius are by far the largest source of optical thickness uncertainty, although uncertainties from effective variance, real refractive index and the correlation between effective radius and variance are also large contributors. It appears that the problems associated with a proper retrieval of the size distribution cascade down to the uncertainty analysis for optical depth. Even so, optical depth retrievals match in situ observations very well, and do not exhibit a sampling variability that is consistent with the large uncertainty in optical depth indicated by the analysis. The standard deviation of the set of HSRL assisted retrievals of optical thickness at $532 \mathrm{~nm}$ is 0.05 , which is far smaller than the mean assessed uncertainty, 0.39 . This indicates that the assessment of optical thickness uncertainty is too high.

It is possible that our observation error covariance matrix, $\mathbf{C}_{T}$, is too large. A breakdown of the relative magnitude of the components of Eq. (3) shows that the error due to aircraft pitch angle, $\mathbf{C}_{\mathrm{p}}$, is the largest contributer to the total error covariance matrix. This is based upon a rather arbitrary selection of $0.5^{\circ}$ as the error in pitch angle. As described in Sect. 3, the Inertial Monitoring Unit (IMU) onboard the B-200 was not very accurate (and has since been replaced), so we needed to correct the heading and pitch angles. We did so by confirming that various features in observed data were aligned properly, including the polarization azimuth. We then chose the uncertainty in pitch and heading angle $\left(0.5^{\circ}\right.$ each) to represent our best guess for our accuracy during that alignment. It is possible that we chose too large of an error for the pitch angle. Reducing the pitch angle error to $0.1^{\circ}$ significantly reduces the assessed error. If this is done for our sample segment (170), the norm of the error covariance matrix is reduced by $32 \%$ and the optical thickness error is reduced from $46.6 \%$ to $35.1 \%$. Pitch angle error reduction affects nearly all parameters, but the greatest impact is for optical thickness, as is displayed in Table 7. In that table, we also show the uncertainties computed without any geometry related errors (as will presumably be the case for orbital sensors). Uncertainties are further reduced, although optical thickness still has a relatively large $28.2 \%$ error. Another large contributer to $\mathbf{C}_{T}$ was $\mathbf{C}_{\mathrm{ag}}$, which we included to account for the variability of the set of scans we averaged for 
Table 7. Percent error for the segment 170 retrieval with HSRL data. The first row represents the original uncertainty assessment. The second is the uncertainty if the error covariance matrix is altered to represent a pitch angle uncertainty reduction from $0.5^{\circ}$ to $0.1^{\circ}$. The last row represents the uncertainty if there is no contribution to the error covariance matrix from heading or pitch error.

\begin{tabular}{lcccccccc}
\hline & $\tau$ & $\varpi$ & $n_{\mathrm{f}}$ & $\mathcal{R}\left(m_{\mathrm{f}}\right)$ & $\mathcal{I}\left(m_{\mathrm{f}}\right)$ & $r_{\mathrm{e}, \mathrm{f}}$ & $v_{\mathrm{e}, \mathrm{f}}$ & $n_{\mathrm{c}}$ \\
\hline Original $\mathbf{C}_{T}$ & $46.6 \%$ & $2.3 \%$ & $10.8 \%$ & $5.0 \%$ & $0.4 \%$ & $1.8 \%$ & $3.0 \%$ & $0.2 \%$ \\
$\sigma_{\phi}=0.1^{\circ}$ & $35.1 \%$ & $1.7 \%$ & $10.8 \%$ & $3.6 \%$ & $0.3 \%$ & $1.3 \%$ & $2.3 \%$ & $0.2 \%$ \\
$\mathbf{C}_{y}=\mathbf{C}_{\mathrm{p}}=0$ & $28.2 \%$ & $1.3 \%$ & $10.8 \%$ & $2.9 \%$ & $0.2 \%$ & $1.1 \%$ & $1.8 \%$ & $0.1 \%$ \\
\hline
\end{tabular}

Table A1. Retrieval segment location, time, and solar and instrument geometry. Altitude is in meters above sea level. Optimizations without HSRL data for segments marked with a * were deemed "unsuccessful".

\begin{tabular}{lccccccccc}
\hline Starting Scan & index & UTC time & Latitude & Longitude & Heading & Track & Solar Azimuth & Solar Zenith & Altitude \\
\hline $160^{*}$ & 0 & $20: 28: 54$ & 58.040 & -104.606 & 259.7 & 240.0 & 213.2 & 38.3 & 8681 \\
165 & 1 & $20: 29: 03$ & 58.036 & -104.618 & 256.3 & 237.0 & 213.2 & 38.3 & 8681 \\
$170^{*}$ & 2 & $20: 29: 11$ & 58.032 & -104.628 & 255.1 & 234.5 & 213.2 & 38.3 & 8680 \\
175 & 3 & $20: 29: 20$ & 58.028 & -104.639 & 251.8 & 230.9 & 213.3 & 38.3 & 8680 \\
180 & 4 & $20: 29: 28$ & 58.024 & -104.649 & 250.0 & 230.0 & 213.3 & 38.3 & 8681 \\
$185^{*}$ & 5 & $20: 29: 37$ & 58.019 & -104.660 & 248.2 & 226.7 & 213.4 & 38.3 & 8681 \\
190 & 6 & $20: 29: 45$ & 58.014 & -104.669 & 246.5 & 225.0 & 213.4 & 38.3 & 8681 \\
$195^{*}$ & 7 & $20: 29: 53$ & 58.008 & -104.680 & 246.6 & 224.3 & 213.4 & 38.3 & 8682 \\
$200^{*}$ & 8 & $20: 30: 02$ & 58.003 & -104.689 & 246.5 & 222.3 & 213.5 & 38.3 & 8683 \\
$205^{*}$ & 9 & $20: 30: 10$ & 57.997 & -104.699 & 244.4 & 223.0 & 213.5 & 38.3 & 8683 \\
210 & 10 & $20: 30: 19$ & 57.992 & -104.708 & 249.4 & 222.6 & 213.6 & 38.3 & 8684 \\
$215^{*}$ & 11 & $20: 30: 27$ & 57.986 & -104.718 & 244.1 & 222.3 & 213.6 & 38.3 & 8683 \\
$220^{*}$ & 12 & $20: 30: 35$ & 57.981 & -104.728 & 243.9 & 223.1 & 213.6 & 38.3 & 8685 \\
$225^{*}$ & 13 & $20: 30: 44$ & 57.975 & -104.738 & 240.4 & 223.4 & 213.7 & 38.3 & 8687 \\
230 & 14 & $20: 30: 52$ & 57.969 & -104.747 & 242.1 & 223.3 & 213.7 & 38.3 & 8687 \\
235 & 15 & $20: 31: 01$ & 57.964 & -104.757 & 242.7 & 222.1 & 213.8 & 38.3 & 8686 \\
$240^{*}$ & 16 & $20: 31: 09$ & 57.958 & -104.767 & 241.8 & 222.6 & 213.8 & 38.3 & 8686 \\
$245^{*}$ & 17 & $20: 31: 18$ & 57.952 & -104.777 & 240.9 & 222.5 & 213.8 & 38.3 & 8687 \\
\hline
\end{tabular}

each segment. $\mathbf{C}_{\mathrm{ag}}$ is not as large as $\mathbf{C}_{\mathrm{p}}$, but its reduction could also bring the optical depth uncertainty down to a level that is more consistent with what one would expect based on sampling uncertainty. In other scenarios, averaging over a greater number of scans would reduce $\mathbf{C}_{\mathrm{ag}}$, but because of the large spatial variability we encountered in this plume we did not take this additional step.

\section{Conclusions}

In this paper, we have retrieved aerosol parameters of smoke from recent boreal forest fires. This is a particularly difficult type of aerosol to retrieve because it is both absorbing and unevenly distributed vertically, which is information that is difficult to retrieve simultaneously. We tested the utility of lidar data when calculating optimal estimates of aerosol properties using our airborne polarimeter. To do so, we did about twenty retrievals on data collected when our instrument, the RSP, was overflying a fresh smoke plume. We performed these retrievals with the RSP data alone, and then repeated them using information gathered by a lidar instrument called the HSRL. This information included observations of the altitude of the elevated aerosol layer and the aerosol column optical depth. The latter was used to compute the initial value for number concentration during optimization, while the aerosol layer altitude was held fixed with the structure determined by the lidar.

We retrieved aerosol properties that are characteristic of boreal forest fire smoke when our optimizations were constrained by HSRL data. These aerosol properties compared well to a variety of in situ observations measured concurrently within the smoke plume. Retrievals performed without HSRL data were successful (in terms of matching the HSRL constrained retrievals) only about half of the time. While "successful" retrievals without HSRL data were nearly identical to retrievals performed with the aid of HSRL data, "unsuccessful" retrievals found aerosols that were small (but with very wide size distributions and an excess of small particles) with unusually large real and imaginary modes of the complex refractive index (the latter indicating significant absorption). These "unsuccessful" retrievals occur because the 
initial number concentration value is too far from the actual solution and the optimization became trapped in a local minimum. HSRL estimates of aerosol optical depth (and thus number concentration) were therefore an important factor in retrieval success, and resulted in more consistent and stable results for the set of analyzed scenes.

This work presents a strong argument that operational remote sensing of high loads of small particles with instruments such as the Aerosol Polarimetry Sensor will require either an independent estimate of number concentration, or the help of a table lookup to provide an initial value. Otherwise, incorrect values may be retrieved for refractive index and size, although it is important to note that mean retrieval single scattering albedos with and without HSRL data are within uncertainty ranges. In all cases the spectral optical depth retrievals were consistent with AATS-14 measurements. Despite the substantially different microphysical retrievals, this retrieved property is robust. Aerosol vertical distribution does not appear as important as it was for the smoke aerosols analyzed by Waquet et al. (2009), but this may be due to the large vertical extent and weak absorption of this boreal forest fire smoke.

We have also demonstrated the importance of an accurate understanding of aircraft geometry for retrievals such as this. Our error estimate of $0.5^{\circ}$ for the view zenith angle was the largest contributor to our error covariance matrix and is responsible for the very large estimate of uncertainty for aerosol optical thickness (although it contributed to the uncertainty of all retrieved parameters).

The RSP and HSRL instruments remain on the B-200 aircraft despite the failure of the NASA Glory satellite launch. Future field campaigns including in situ measurement instrumentation will have the capability to repeat the comparison methods presented here, and hopefully establish the utility of future scanning polarimeter observations for a variety of aerosol types.

Acknowledgements. The first author acknowledges support from the US National Science Foundation, through a Fellowship in the IGERT Joint Program in Applied Mathematics and Earth and Environmental Science at Columbia University at the time of the MILAGRO field campaign. His graduate studies was also funded by the NASA Glory project. Currently, both he and M. Ottaviani are supported by an appointment to the NASA Postdoctoral Program at the NASA Goddard Institute for Space Studies, administered by Oak Ridge Associated Universities through a contract with NASA. We would like to thank the B-200 pilot, Les Kagey, flight engineer, Mike Wusk, aircraft crew chief Dale Bowser and the rest of the B-200 support team for their energy and professionalism during ARCTAS. This research was carried out with funding from the NASA Glory project. NASA B-200, RSP and HSRL participation in ARCTAS was funded by the NASA Radiation Sciences Program, managed by Hal Maring. MODIS imagery was provided by the NASA GSFC Rapid Response System.

Edited by: V. F. McNeill

\section{References}

Abel, S., Haywood, J., Highwood, E., Li, J., and Buseck, P.: Evolution of biomass burning aerosol properties from an agricultural fire in southern Africa., Geophys. Res. Lett., 30, 1783-1787, 2003.

Andreae, M. O. and Gelencsér, A.: Black carbon or brown carbon? The nature of light-absorbing carbonaceous aerosols, Atmos. Chem. Phys., 6, 3131-3148, doi:10.5194/acp-6-3131-2006, 2006.

Bergstrom, R. W., Schmidt, K. S., Coddington, O., Pilewskie, P., Guan, H., Livingston, J. M., Redemann, J., and Russell, P. B.: Aerosol spectral absorption in the Mexico City area: results from airborne measurements during MILAGRO/INTEX B, Atmos. Chem. Phys., 10, 6333-6343, doi:10.5194/acp-10-63332010, 2010.

Breon, F., Tanre, D., Lecomte, P., and Herman, M.: Polarized reflectance of bare soils and vegetation: measurementsand models, IEEE T. Geosci. Remote, 33, 487-499, 1995.

Cairns, B.: Polarimetric Remote Sensing of Aerosols, IEEE T. Geosci. Remote, 1, 518-520, 2003.

Cairns, B., Carlson, B., Lacis, A., and Russell, E.: Analysis of ground-based polarimetric sky radiance measurements, Proc. SPIE, 3121, 382-393, 1997.

Canada: Forest Fire Conditions for June 20 to June 30, 2008, http://cwfis.cfs.nrcan.gc.ca/en_CA/, last access: 18 July 2011, Canadian Wildland Fire Information System (CWFIS), 2009.

Chowdhary, J., Cairns, B., Mishchenko, M., and Travis, L.: Retrieval of aerosol properties over the ocean using multispectral and multiangle photopolarimetric measurements from the Research Scanning Polarimeter, Geophys. Res. Lett., 28, 243-246, 2001.

Chowdhary, J., Cairns, B., and Travis, L.: Case Studies of Aerosol Retrievals over the Ocean from Multiangle, Multispectral Photopolarimetric Remote Sensing Data, J. Atmos. Sci., 59, 383397, 2002.

Chowdhary, J., Cairns, B., Mishchenko, M., Hobbs, P., Cota, G., Redemann, J., Rutledge, K., Holben, B., and Russell, E.: Retrieval of Aerosol Scattering and Absorption Properties from Photopolarimetric Observations over the Ocean during the CLAMS Experiment, J. Atmos. Sci., 62, 1093-1117, 2005a.

Chowdhary, J., Cairns, B., Mishchenko, M., and Travis, L.: Using multi-angle multispectral photo-polarimetry of the NASA Glory mission to constrain optical properties of aerosols and clouds: results from four field experiments, Proc. SPIE, 5978, 1-12, 2005b.

Clarke, A., Varner, J., Eisele, F., Mauldin, R., Tanner, D., and Litchy, M.: Particle production in the remote marine atmosphere: Cloud outflow and subsidence during ACE 1, J. Geophys. Res.Atmos., 103, 16397-16409, 1998.

Clarke, A., McNaughton, C., Kapustin, V., Shinozuka, Y., Howell, S., Dibb, J., Zhou, J., Anderson, B., Brekhovskikh, V., Turner, H., and Pinkerton, M.: Biomass burning and pollution aerosol over North America: Organic components and their influence on spectral optical properties and humidification response, J. Geophys. Res., 112, 1-13, 2007.

De Haan, J., Bosma, P., and Hovenier, J.: The adding method for multiple scattering calculations of polarized light, Astron. Astrophys., 183, 371-391, 1987. 
Dubovik, O., Holben, B., Eck, T., Smirnov, A., Kaufman, Y., King, M., Tanré, D., and Slutsker, I.: Variability of absorption and optical properties of key aerosol types observed in worldwide locations, J. Atmos. Sci., 59, 590-608, 2002.

Duforêt, L., Frouin, R., and Dubuisson, P.: Importance and estimation of aerosol vertical structure in satellite ocean-color remote sensing, Appl. Optics, 46, 1107-1119, 2007.

Dusek, U., Frank, G., Hildebrandt, L., Curtius, J., Schneider, J., Walter, S., Chand, D., Drewnick, F., Hings, S., Jung, D., Borrmann, S., and Andreae, M.: Size matters more than chemistry for cloud-nucleating ability of aerosol particles, Science, 312, 1375-1378, 2006.

Eck, T., Holben, B., Reid, J., O’Neill, N., Schafer, J., Dubovik, O., Smirnov, A., Yamasoe, M., and Artaxo, P.: High aerosol optical depth biomass burning events: A comparison of optical properties for different source regions, Geophys. Res. Lett., 30, 20352039, 2003.

Eck, T., Holben, B., Reid, J., Sinyuk, A., Hyer, E., O’Neill, N., Shaw, G., Castle, J., Chapin, F., Dubovik, O., Smirnov, A., Vermote, E., Schafer, J., Giles, D., Slutsker, I., Sorokine, M., and Newcomb, W.: Optical properties of boreal region biomass burning aerosols in central Alaska and seasonal variation of aerosol optical depth at an Arctic coastal site, J. Geophys. Res., 114, 114, 2009.

Elias, T., Cairns, B., and Chowdhary, J.: Surface optical properties measured by the airborne research scanning polarimeter during the CLAMS experiment, in: Remote Sensing of Clouds and the Atmosphere VIII, edited by: Schaefer, K., Comeron, A., Carleer, M. R. and Picard, R. H., Proc. SPIE,, 5235, 595-606, 2004.

Fletcher, R.: A Modified Marquardt Subroutine for Non-Linear Least Squares, Tech. rep., United Kingdom Atomic Energy Authority, Theoretical Physics Division, Atomic Energy Research Establishment, Harwell, Berkshire, UK, 1971.

Fuelberg, H. E., Harrigan, D. L., and Sessions, W.: A meteorological overview of the ARCTAS 2008 mission, Atmos. Chem. Phys., 10, 817-842, doi:10.5194/acp-10-817-2010, 2010.

Gatebe, C., King, M., Tsay, S., Ji, Q., Arnold, G., and Li, J.: Sensitivity of off-nadir zenith angles to correlation between visible and near-infrared reflectance for use in remote sensing of aerosol over land, IEEE T. Geosci. Remote, 39, 805-819, 2001.

Grant, L.: Diffuse and specular characteristics of leaf reflectance, Remote Sens. Environ., 22, 309-322, 1987.

Guanter, L., Gómez-Chova, L., and Moreno, J.: Coupled retrieval of aerosol optical thickness, columnar water vapor and surface reflectance maps from ENVISAT/MERIS data over land, Remote Sens. Environ., 112, 2898-2913, 2008.

Hair, J. W., Caldwell, L. M., Krueger, D. A., and She, C.-Y.: HighSpectral-Resolution Lidar with Iodine-Vapor Filters: Measurement of Atmospheric-State and Aerosol Profiles, Appl. Optics, 40, 5280-5294, 2001.

Hair, J. W., Hostetler, C. A., Cook, A. L., Harper, D. B., Ferrare, R. A., Mack, T. L., Welch, W., Izquierdo, L. R., and Hovis, F. E.: Airborne High Spectral Resolution Lidar for profiling aerosol optical properties, Appl. Optics, 47, 6734-6752, 2008.

Hansen, J. and Hovenier, J.: Interpretation of the Polarization of Venus, J. Atmos. Sci., 31, 1137-1160, 1974.

Hansen, J. and Travis, L.: Light scattering in planetary atmospheres, Space Sci. Rev., 16, 527-610, 1974.
Hasekamp, O. P.: Capability of multi-viewing-angle photopolarimetric measurements for the simultaneous retrieval of aerosol and cloud properties, Atmos. Meas. Tech., 3, 839-851, doi:10.5194/amt-3-839-2010, 2010.

Hasekamp, O. and Landgraf, J.: Retrieval of aerosol properties over land surfaces: capabilities of multiple-viewing-angle intensity and polarization measurements, Appl. Optics, 46, 3332-3344, 2007.

Hebden, M.: An Algorithm for Minimization Using Exact Second Derivatives, Tech. Rep. TP515, Atomic Energy Research Establishment, Harwell, England, 1973.

Hsu, N., Tsay, S., King, M., and Herman, J.: Deep blue retrievals of Asian aerosol properties during ACE-Asia, IEEE T. Geosci. Remote, 44, 3180-3195, 2006.

IPCC: Climate Change 2007 - The Physical Science Basis : Contribution of the Working Group I to the Fourth Assessment Report of the IPCC, Cambridge University Press, New York, NY, 2007.

Jacob, D. J., Crawford, J. H., Maring, H., Clarke, A. D., Dibb, J. E., Emmons, L. K., Ferrare, R. A., Hostetler, C. A., Russell, P. B., Singh, H. B., Thompson, A. M., Shaw, G. E., McCauley, E., Pederson, J. R., and Fisher, J. A.: The Arctic Research of the Composition of the Troposphere from Aircraft and Satellites (ARCTAS) mission: design, execution, and first results, Atmos. Chem Phys., 10, 5191-5212, doi:10.5194/acp-10-5191-2010, 2010.

Kaufman, Y., Wald, A., Remer, L., Gao, B., Li, R., and Flynn, L.: The MODIS 2.1- $\mu \mathrm{m}$ channel-correlation with visible reflectancefor use in remote sensing of aerosol, IEEE T. Geosci. Remote, 35, 1286-1298, 1997.

Kawata, Y.: Circular polarization of sunlight reflected by planetary atmospheres, Icarus, 33, 217-232, 1978.

Kirchstetter, T., Novakov, T., and Hobbs, P.: Evidence that the spectral dependence of light absorption by aerosols is affected by organic carbon, J. Geophys. Res.-Atmos., 109, 1-12, 2004.

Knobelspiesse, K., Pietras, C., Fargion, G., Wang, M., Frouin, R., Miller, M., Subramaniam, A., and Balch, W.: Maritime aerosol optical thickness measured by handheld sun photometers, Remote Sens. Environ., 93, 87-106, 2004.

Knobelspiesse, K., Cairns, B., Schaaf, C., Schmid, B., and Román, M.: Surface BRDF estimation from an aircraft compared to MODIS and ground estimates at the Southern Great Plains site, J. Geophys. Res., 113, 1-21, 2008.

Koppmann, R., von Czapiewski, K., and Reid, J. S.: A review of biomass burning emissions, part I: gaseous emissions of carbon monoxide, methane, volatile organic compounds, and nitrogen containing compounds, Atmos. Chem. Phys. Discuss., 5, 10455 10516, doi:10.5194/acpd-5-10455-2005, 2005.

Lebsock, M., L'Ecuyer, T., and Stephens, G.: Information content of near-infrared spaceborne multiangular polarization measurements for aerosol retrievals, J. Geophys. Res., 112, 1-14, 2007.

Lewis, K., Arnott, W. P., Moosmuller, H., and Wold, C. E.: Strong spectral variation of biomass smoke light absorption and single scattering albedo observed with a novel dual-wavelength photoacoustic instrument, J. Geophys. Res., 113, D16203, doi:10.1029/2007JD009699, 2008.

Liu, L., Mishchenko, M., and Patrick Arnott, W.: A study of radiative properties of fractal soot aggregates using the superposition T-matrix method, J. Quant. Spectrosc. Ra., 109, 2656-2663, 2008. 
Livingston, J. M., Redemann, J., Russell, P. B., Torres, O., Veihelmann, B., Veefkind, P., Braak, R., Smirnov, A., Remer, L., Bergstrom, R. W., Coddington, O., Schmidt, K. S., Pilewskie, P., Johnson, R., and Zhang, Q.: Comparison of aerosol optical depths from the Ozone Monitoring Instrument (OMI) on Aura with results from airborne sunphotometry, other space and ground measurements during MILAGRO/INTEX-B, Atmos. Chem. Phys., 9, 6743-6765, doi:10.5194/acp-9-6743-2009, 2009.

Lucht, W., Schaaf, C., and Strahler, A.: An algorithm for the retrieval of albedo from space using semiempirical BRDF models, IEEE T. Geosci. Remote, 38, 977-998, 2000.

Markwardt, C.: Non-linear Least Squares Fitting in IDL with MPFIT, Astronomical Society of the Pacific Conference Series, 411, 251-254, 2009.

Martins, J., Hobbs, P., Weiss, R., and Artaxo, P.: Sphericity and morphology of smoke particles from biomass burning in Brazil, J. Geophys. Res.-Atmos., 103, 32051-32057, 1998.

McNaughton, C., Clarke, A., Howell, S., Pinkerton, M., Anderson, B., Thornhill, L., Hudgins, C., Winstead, E., Dibb, J., Scheuer, E., and Maring, H.: Results from the DC-8 inlet characterization experiment (DICE): Airborne versus surface sampling of mineral dust and sea salt aerosols, Aerosol Sci. Tech., 41, 136-159, 2007.

McNaughton, C. S., Clarke, A. D., Kapustin, V., Shinozuka, Y., Howell, S. G., Anderson, B. E., Winstead, E., Dibb, J., Scheuer, E., Cohen, R. C., Wooldridge, P., Perring, A., Huey, L. G., Kim, S., Jimenez, J. L., Dunlea, E. J., DeCarlo, P. F., Wennberg, P. O., Crounse, J. D., Weinheimer, A. J., and Flocke, F.: Observations of heterogeneous reactions between Asian pollution and mineral dust over the Eastern North Pacific during INTEX-B, Atmos. Chem. Phys., 9, 8283-8308, doi:10.5194/acp-9-8283-2009, 2009.

Mishchenko, M. and Travis, L.: Gustav Mie and the evolving discipline of electromagnetic scattering by particles, B. Am. Meteorol. Soc., 89, 1853-1861, 2008.

Mishchenko, M., Cairns, B., Hansen, J., Travis, L., Burg, R., Kaufman, Y., Vanderlei Martins, J., and Shettle, E.: Monitoring of aerosol forcing of climate from space: analysis of measurement requirements, J. Quant. Spectrosc. Ra., 88, 149-161, 2004.

Mishchenko, M., Cairns, B., Kopp, G., Schueler, C., Fafaul, B., Hansen, J., Hooker, R., Itchkawich, T., Maring, H., and Travis, L.: Accurate monitoring of terrestrial aerosols and total solar irradiance: introducing the Glory mission, B. Am. Meteorol. Soc., 88, 687-691, 2007a.

Mishchenko, M., Geogdzhayev, I., Cairns, B., Carlson, B., Chowdhary, J., Lacis, A., Liu, L., Rossow, W., and Travis, L.: Past, present, and future of global aerosol climatologies derived from satellite observations: A perspective, J. Quant. Spectrosc. Ra., 106, 325-347, 2007b.

Moré, J.: The Levenberg-Marquardt Algorithm: Implementation and Theory, in: Lecture Notes in Mathematics: Numerical Analysis, edited by: Watson, G. A., Proceedings of the Biennial Conference Held at Dundee, Springer-Verlag, Berlin, vol. 630, 105116, 1977.

Moré, J. J., Garbow, B. S., and Hillstrom, K. E.: User Guide for MINPACK-1, Argonne National Laboratory Report ANL-80-74, Argonne, Ill., 1980.
Müller, D., Mattis, I., Wandinger, U., Ansmann, A., Althausen, D., and Stohl, A.: Raman lidar observations of aged Siberian and Canadian forest fire smoke in the free troposphere over Germany in 2003: Microphysical particle characterization, J. Geophys. Res., 110, 17201, 2005.

Müller, D., Mattis, I., Ansmann, A., Wandinger, U., Ritter, C., and Kaiser, D.: Multiwavelength Raman lidar observations of particle growth during long-range transport of forest-fire smoke in the free troposphere, Geophys. Res. Lett., 34, 1-4, 2007.

Nadal, F. and Breon, F.-M.: Parameterization of Surface Polarized Reflectance Derived from POLDER Spaceborne Measurements, IEEE T. Geosci. Remote, 37, 1709, 1999.

O’Neill, N., Ignatov, A., Holben, B., and Eck, T.: The lognormal distribution as a reference for reporting aerosol optical depth statistics: Empirical tests using multi-year, multi-site AERONET sunphotometer data, Geophys. Res. Lett., 27, 3333-3336, 2000.

Redemann, J., Schmid, B., Eilers, J., Kahn, R., Levy, R., Russell, P., Livingston, J., Hobbs, P., Smith, W., and Holben, B.: Suborbital measurements of spectral aerosol optical depth and its variability at subsatellite grid scales in support of CLAMS 2001, J. Atmos. Sci., 62, 993-1007, 2005.

Reid, J. and Hobbs, P.: Physical and optical properties of young smoke from individual biomass fires in Brazil, J. Geophys. Res.Atmos., 103, 32013-32030, 1998.

Reid, J., Hobbs, P., Ferek, R., Blake, D., Martins, J., Dunlap, M., and Liousse, C.: Physical, chemical, and optical properties of regional hazes dominated by smoke in Brazil, J. Geophys. Res.Atmos., 103, 32059-32080, 1998.

Reid, J. S., Eck, T. F., Christopher, S. A., Koppmann, R., Dubovik, O., Eleuterio, D. P., Holben, B. N., Reid, E. A., and Zhang, J.: A review of biomass burning emissions part III: intensive optical properties of biomass burning particles, Atmos. Chem. Phys., 5, 827-849, doi:10.5194/acp-5-827-2005, 2005a.

Reid, J. S., Koppmann, R., Eck, T. F., and Eleuterio, D. P.: A review of biomass burning emissions part II: intensive physical properties of biomass burning particles, Atmos. Chem. Phys., 5, 799825, doi:10.5194/acp-5-799-2005, 2005 b.

Remer, L., Wald, A., and Kaufman, Y.: Angular and seasonal variation of spectral surface reflectanceratios: implications for the remote sensing of aerosol over land, IEEE T. Geosci. Remote, 39, 275-283, 2001.

Rodgers, C.: Inverse Methods for Atmospheric Sounding: Theory and Practice, World Scientific, Singapore, 2000.

Rogers, R. R., Hair, J. W., Hostetler, C. A., Ferrare, R. A., Obland, M. D., Cook, A. L., Harper, D. B., Burton, S. P., Shinozuka, Y., McNaughton, C. S., Clarke, A. D., Redemann, J., Russell, P. B., Livingston, J. M., and Kleinman, L. I.: NASA LaRC airborne high spectral resolution lidar aerosol measurements during MILAGRO: observations and validation, Atmos. Chem. Phys., 9, 4811-4826, doi:10.5194/acp-9-4811-2009, 2009.

Russell, P., Livingston, J., Hignett, P., Kinne, S., Wong, J., Chien, A., Bergstrom, R., Durkee, P., and Hobbs, P.: Aerosol-induced radiative flux changes off the United States mid-Atlantic coast: Comparison of values calculated from sunphotometer and in situ data with those measured by airborne pyranometer, J. Geophys. Res.-Atmos., 104, 2289-2307, 1999. 
Russell, P. B., Bergstrom, R. W., Shinozuka, Y., Clarke, A. D., DeCarlo, P. F., Jimenez, J. L., Livingston, J. M., Redemann, J., Dubovik, O., and Strawa, A.: Absorption Angstrom Exponent in AERONET and related data as an indicator of aerosol composition, Atmos. Chem. Phys., 10, 1155-1169, doi:10.5194/acp10-1155-2010, 2010.

Schmid, B., Redemann, J.,Russell, P. B., Hobbs, P. V., Hlavka, D. L., McGill, M. J., Holben, B. N., Welton, E. J., Campbell, J. R., Torres, O., Kahn, R. A., Diner, D. J., Helmlinger, M. C., Chu, D. A., Robles-Gonzalez, C., and de Leeuw, G.: Coordinated airborne, spaceborne, and ground-based measurements of massive, thick aerosol layers during the dry season in Southern Africa, J. Geophys. Res, 108, 8496, 2003.

Schmid, B., Ferrare, R., Flynn, C., Elleman, R., Covert, D., Strawa, A., Welton, E., Turner, D., Jonsson, H., Redemann, J., Eilers, J., Ricci, K., Hallar, A. G., Clayton, M., Michalsky, J., Smirnov, A., Holben, B., and Barnard, J.: How well do state-ofthe-art techniques measuring the vertical profile of tropospheric aerosol extinction compare, J. Geophys. Res., 111, D05207, doi:10.1029/2005JD005837, 2006.

Shinozuka, Y., Redemann, J., Livingston, J. M., Russell, P. B., Clarke, A. D., Howell, S. G., Freitag, S., O’Neill, N. T., Reid, E. A., Johnson, R., Ramachandran, S., McNaughton, C. S., Kapustin, V. N., Brekhovskikh, V., Holben, B. N., and McArthur, L. J. B.: Airborne observation of aerosol optical depth during ARCTAS: vertical profiles, inter-comparison and fine-mode fraction, Atmos. Chem. Phys., 11, 3673-3688, doi:10.5194/acp-11-36732011, 2011.
Vanderbilt, V. and Grant, L.: Photon-vegetation interactions: applications in optical remote sensing and plant ecology, chap. Polarization of Light by Vegetation, Springer-Verlag, Berlin, New York, 194-228, 1991.

Vanderbilt, V., Grant, L., Biehl, L. L., and Robinson, B. F.: Specular, diffuse, and polarized light scattered by two wheat canopies, Appl. Optics, 24, 2408-2418, 1985.

Virkkula, A., Ahlquist, N., Covert, D., Arnott, W., Sheridan, P., Quinn, P., and Coffman, D.: Modification, calibration and a field test of an instrument for measuring light absorption by particles, Aerosol Sci. Tech., 39, 68-83, 2005.

Waquet, F., Cairns, B., Knobelspiesse, K., Chowdhary, J., Travis, L., Schmid, B., and Mishchenko, M.: Polarimetric remote sensing of aerosols over land, J. Geophys. Res., 114, D01206, doi:10.1029/2008JD010619, 2009.

Winker, D., Pelon, J., and McCormick, M.: The CALIPSO mission: Spaceborne lidar for observation of aerosols and clouds, Int. Soc. Opt. Eng., 4893, 1-11, 2003.

Winker, D., Hunt, W., and Hostetler, C.: Status and performance of the CALIOP lidar, Int. Soc. Opt. Eng., 5575, 8-15, 2004.

Winker, D., Hunt, W., and McGill, M.: Initial performance assessment of CALIOP, Geophys. Res. Lett., 34, 19, 2007. 